\title{
CINE DE PROPAGANDA NAZI EN EL ECUADOR (1934-1941). LA CONFRONTACIÓN IDEOLÓGICA POR UN PAÍS
}

Nazi Propaganda Cinema in Ecuador (1934-1941). The Ideological Confrontation for a Country

YAZMÍN ECHEVERRÍA ${ }^{\mathrm{a}}$

Pontificia Universidad Católica del Ecuador, Quito

DOI: $10.15366 /$ secuencias2020.52.005

\section{RESUMEN}

Durante la Segunda Guerra Mundial, América Latina se convirtió en un territorio de confrontación ideológica y política entre los países Aliados y Ejistas. A partir de la ascensión de Hitler al poder en 1933, la influencia de la ideología nacionalsocialista tomó mucha fuerza en toda América Latina. Aparecieron en varios países de la región movimientos y partidos políticos que apoyaban a Hitler y a la unión ejista. Como respuesta, Estados Unidos ejecutó un plan de intervención cultural para frenar el avance del nazismo a través de campañas publicitarias. La presente investigación indaga sobre la expansión de propaganda nazi por fuera de los territorios del Tercer Reich hacia territorios más neutrales como Ecuador, los principales espacios para su difusión y el tipo de cine de propaganda que se estrenó en el país desde 1934 hasta 1941, con el objetivo de descubrir qué tan significativos fueron los estrenos que llegaron al Ecuador durante el conflicto.

Palabras clave: Ecuador, cine, nazismo, exhibición.

\begin{abstract}
During World War II, Latin America became a territory of ideological and political confrontation between Allied and Axis countries. After Hitler's rise to power in 1933, the influence of the National Socialist ideology spread with great strength throughout Latin America. Different movements and political parties that supported Hitler and the Axis union appeared in several countries in the region. In response, the United States executed a cultural intervention plan to stop the advance of Nazism through advertising campaigns. The present article investigates the expansion of Nazi propaganda outside the territories of the Third Reich, in more neutral territories such as Ecuador. It will examine the main spaces of distribution, and the type of propaganda cinema that was released in the country from 1934 to 1941, with the aim to discover how significant were the premieres that came to Ecuador during the conflict.
\end{abstract}

Keywords: Ecuador, cinema, Nazism, exhibition.

[a] Yazmín Echeverría es socióloga especializada en Ciencias Políticas en el Instituto de Altos Estudios Sociales de la Universidad San Martín, Buenos Aires, Argentina. Investigadora de cine y representaciones de la violencia en América Latina, publicó un artículo en la revista digital Tránsitos. Fue ganadora del Fondo de Fomento Cinematográfico del Ecuador, categoría «Investigación y publicación» en 2015, publicando un análisis sociológico de cuarenta y cinco años de cine ecuatoriano comprendido durante 1970 y 2015, investigación que desarrolló en colaboración con el Consejo Nacional de Cinematografía del Ecuador y la Cinemateca Nacional. E-mail: yvecheverria@gmail.com. 


\section{Introducción ${ }^{1}$}

El poder persuasivo que tiene la imagen y la capacidad de llegar a enormes cantidades de público hicieron del cine un importante instrumento de propaganda ${ }^{2}$ para el nazismo, no solo porque permitió difundir las ideas del nacionalsocialismo, sino porque su fuerza se centró en productos culturales dirigidos, principalmente, al entretenimiento ${ }^{3}$. El cine del Tercer Reich fue un cine popular, dirigido a entretener a la gente y, sobre todo, a alejar su atención de la Guerra - especialmente, después de la batalla de Stalingrado $(1943)^{4}$ - .

Esta característica, que presentaba al cine de propaganda como supuestamente inofensivo, estableció fuertes estereotipos de la cultura germana y de la cultura judía durante la Guerra. La imagen germánica del ario de ojos azules, rubio, de tez blanca, alto, esbelto y perfil recto asienta el carácter ultrapatriótico de varios personajes de las películas realizadas durante el régimen nazi ${ }^{5}$. Opuestamente, se popularizó el estereotipo del judío con nariz curva y prominente, grandes orejas, cabello negro, piel morena y mentón afilado, como si sus rasgos físicos fueran indicadores directos de su maldad congénita, imagen mostrada en filmaciones como El Judio Eterno (Der ewige Jude, Fritz Hippler, 1940) o El judio Suss (Jud Süß, Veit Harlan, 1940), películas sumamente antisemitas. El cine de propaganda nazi construyó una imagen idealizada de la sociedad alemana nacionalsocialista. La ilusión ${ }^{6}$ de compartir un mismo destino colectivo y de encarnar una sola voluntad en la conformación de la Alemania nacional socialista se reflejaba en cada uno de los filmes producidos. A pesar de su fortaleza, la nación estaba gravemente amenazada por un «enemigo», el judío que podía estar tanto dentro como fuera de Alemania, cuya sola presencia podía contaminar a la nación y corromper los «puros» corazones de los ciudadanos. Bajo este paradigma, el régimen nazi justificó progresivamente el rechazo y la persecución a la comunidad judía, tanto dentro de Alemania como en otros países del mundo. El discurso antisemita se difundió en Europa y tuvo acogida también en países de América Latina como Argentina, Brasil, Chile, Ecuador, México, etc.

La Alemania nazi implementó distintas alianzas para influenciar en las cinematografías iberoamericanas mediante filmes hablados en español, como con la creación de la productora Hispano-Film Produktion, la realización de coproducciones con la España fascista y la concesión de varios créditos a productoras argentinas $^{7}$ con el objetivo de aumentar el número de simpatizantes en territorios más neutrales y de incrementar los mercados de influencia del cine europeo - que, por el contexto, era, sobre todo, alemán-. El interés de producir filmes de propaganda a través de producciones locales fomentó relaciones con España, México y Argentina $^{8}$, países que gozaban de saludables estructuras cinematográficas. Ecuador no era el caso.

La presente investigación se centra en la difusión
[1] N. del E.: Los títulos de las películas que se citan en castellano a lo largo del texto corresponden a los de estreno en Ecuador.

[2] Según Hannah Arendt, la propaganda totalitaria construye un mundo ficticio y lógicamente coherente. La propaganda «revela» aquello que no es evidente para los ciudadanos comunes y presenta principios esenciales como la verdadera motivación del accionar político. Para ello, la propaganda extiende su campo de acción y busca el control estricto de aspectos de la vida social que, hasta el momento, han gozado de una relativa independencia: la educación, la información, el arte y, por supuesto, el entretenimiento. Para el nazismo, el cine no era el todo del sistema de propaganda, era parte de un plan de entretenimiento y diversiones que incluyeron espectáculos, días festivos, conmemoraciones, festivales, etc. Véase Hannah Arendt, Los orígenes del totalitarismo, Parte III: «Totalitarismo» (Madrid, Alianza, 1987).

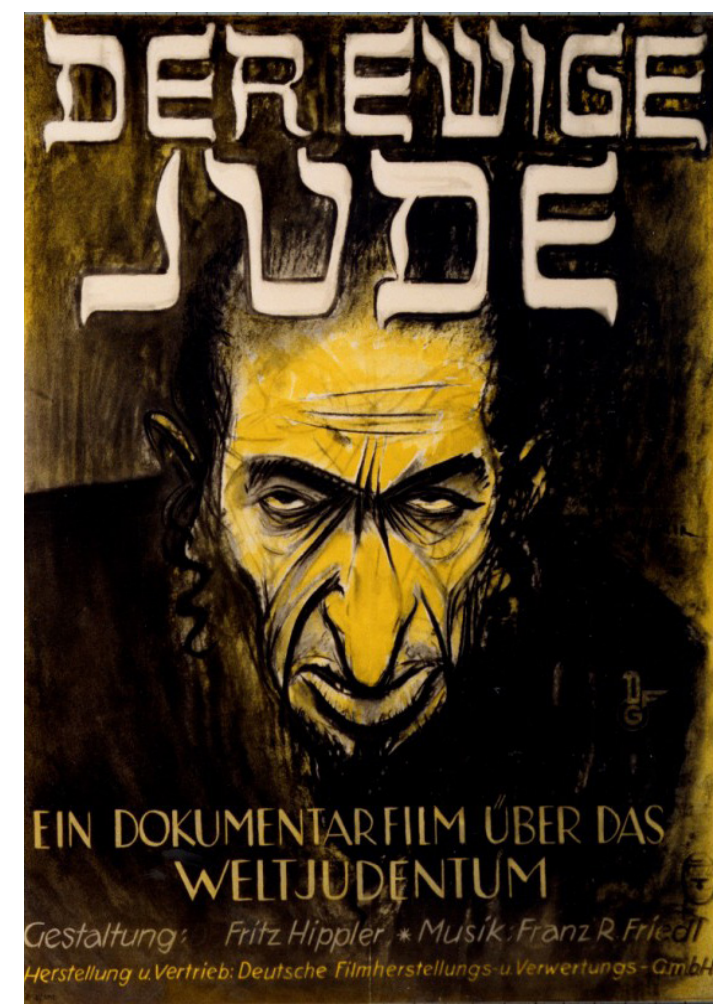

Cartel de El Judío Eterno (Der ewige Jude, Fritz Hippler, 1940). 
[3] Véase Linda Schulte Sasse, Entertaining the Third Reich: Illusions of Wholeness in Nazi Cinema (Durham NC: Duke University Press, 1996).

[4] Eric Rentschler, The Ministry of Illusion. Nazi Cinema and its Afterlife (Cambridge, Harvard University Press, 1996), p. 9.

[5] Como Kolberg (Veit Harlan, 1945), que enseñaba a los alemanes que es preferible morir a rendirse.

[6] Eric Rentschler, The Ministry of Illusion, p.12

[7] Francisco Peredo-Castro, «Las cinematografías iberoamericanas en la encrucijada 19301942» (Archivos de la Filmoteca, n. ${ }^{\circ} 40$, febrero, 2002), p. 126-147.

[8] Lisa Jarvinen y Francisco Peredo-Castro, «Penetrating the Spanish-Speaking Film Markets, 1936-1942», en Roel Vande Winkel y David Welch, Cinema and the Swastika. The International Expansion of Third Reich Cinema (Londres, Palgrave Macmillan, 2011), p.53.

[9] Eric Rentschler, The Ministry of Illusion, p. 271.

[10] Después del ataque de Pearl Harbor en 1941, Estados Unidos declaró abiertamente la guerra contra los países del Eje. La introducción de Estados Unidos en el conflicto implicó la ruptura de relaciones diplomáticas de los países de América con los países del Eje; también se implementó la Lista Negra, en la que se procesaron a simpatizantes del nazismo, tanto individuos como empresas. Esto cerró totalmente las posibilidades de Alemania a establecer relaciones con las industrias fílmicas latinoamericanas, tanto para la producción como para la difusión de películas germanas. Véase Lisa Jarvinen y Francisco Peredo-Castro, «Penetrating the Spanish-Speaking Film Markets, 1936-1942», p.54. de cine alemán y, en particular, de las películas germanas consideradas de "propaganda nazi» en el Ecuador durante la Segunda Guerra Mundial, con el objetivo principal de descubrir el tipo de películas que llegaron a estrenarse en el país y cuáles fueron las repercusiones sociales y culturales de este tipo de cine de propaganda.

Para ello, se recurrió a dos listas de películas de propaganda nazi que, actualmente, se encuentran prohibidas o cuya exhibición es controlada. La primera lista de películas fue realizada por los Aliados en la década de 1950 en donde constan largometrajes prohibidos. Es preciso aclarar que, inicialmente, los Aliados prohibieron alrededor de setecientos filmes en 1949 que fueron considerados de propaganda nazi y ofensivos para otras naciones. Poco a poco, se revisaron los filmes, y algunos fueron retirados de la lista: para 1953, constaban trescientos cuarenta filmes alemanes producidos entre 1930 y 1945; para 1954, doscientas setenta y cinco películas permanecían en la lista; en 1977 había ciento setenta y seis filmes y, para 1995, quedaron entre treinta y treinta y cinco largometrajes del Tercer Reich que todavía estaban prohibidos en Alemania9.

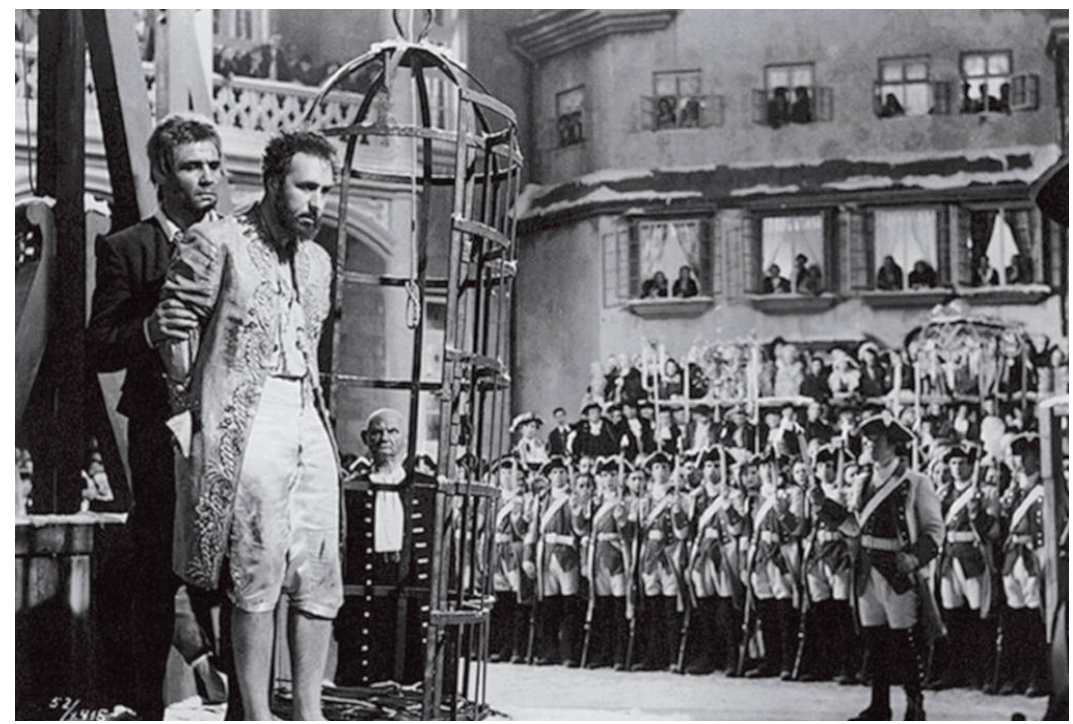

Fotograma de El judío Suss (Jud Süß, Veit Harlan, 1940).

La segunda lista proviene de la Fundación Friedrich Wilhelm Murnau de Alemania, encargada de preservar el acervo cinematográfico nacional desde 1890 hasta 1960. Integra filmes de las mayores productoras alemanas como UFA, Decla, Universium-Film, Bavaria, Terra y Berlin-Film. Las películas registradas en esta lista pueden exhibirse únicamente en eventos cerrados y controlados por la fundación.

Con ambas fuentes, se buscaron en la hemeroteca de la Biblioteca Ecuatoriana Aurelio Espinosa Pólit archivos relacionados con cine en los diarios más destacados: El Comercio de Quito y El Telégrafo de Guayaquil, durante los años 1933 y 1942, ubicando la búsqueda en el periodo previo a la censura impuesta por los aliados después de 1941 con la intromisión de Estados Unidos en el conflicto ${ }^{10}$.

De la misma forma, se utilizaron fuentes documentales y bibliográficas. Las documentales están basadas en archivos e informes políticos hallados en el Archivo Histórico del Ministerio de Relaciones Exteriores Alfredo Pareja Diazcanseco del Ecuador y la Academia Nacional de Historia del Ecuador. 
Respecto a las fuentes bibliográficas utilizadas, se debe mencionar la escasa producción investigativa referente a historia del cine en el país, por lo que se recurrió a investigaciones sobre migración alemana y judía al Ecuador y a investigaciones sobre el movimiento nazi y antinazi ecuatorianos.

Para el procesamiento de información elaboramos matrices de los filmes alemanes estrenados en ambas ciudades y las organizamos cronológicamente para ubicar los estrenos en la coyuntura política. En la construcción de la matriz se consideraron años de estreno, salas de difusión, productora, días de permanencia en salas, propagandas de los filmes en la prensa gráfica y crítica cinematográfica.

En este periodo no existía la crítica de cine en Ecuador ${ }^{11}$, por lo que se realizó un registro de periódicos afines al régimen nazi como El Día, El Debate, Vida Obrera y Regenerador. Del mismo modo, se relevaron los diarios que tuvieron una posición crítica con respecto a Alemania como El Debate y Antinazi, buscando en ellos menciones de los filmes de propaganda nazi ${ }^{12}$.

En la primera sección del artículo se explica el contexto político del Ecuador durante la Segunda Guerra Mundial, integrando la organización del movimiento nazi ecuatoriano y sus principales estrategias de difusión de ideas pronazis en el país. Igualmente, se detalla la conformación Movimiento Antinazi Ecuatoriano y los canales de transmisión de información que fueron establecidos para la defensa de valores democráticos frente al avance del nazismo local.

En la segunda parte, se hace una descripción del desarrollo paulatino que tuvo el cine en la sociedad ecuatoriana y del tipo de mercado cinematográfico local. Por último, se describe la exhibición de películas alemanas en cada año del periodo considerado y, en particular, se destacan los títulos de películas catalogadas como propaganda nazi, para las cuales se proponen breves reseñas.

\section{La situación político-ideológica en Ecuador entre 1930 y 1940}

Durante el periodo de la Segunda Guerra Mundial el Ecuador estuvo marcado por una profunda inestabilidad política: desde 1930 hasta 1948 hubo catorce gobiernos diferentes $^{13}$. La situación se agravó por el conflicto limítrofe entre Ecuador y Perú que estalló el 5 de julio de 1941 con la invasión del ejército peruano a los pueblos de Huaquillas y Charcas y a las provincias de El Oro, Loja, Pastaza y Santiago Zamora. El ejército ecuatoriano no contaba con la fuerza armamentística necesaria para un enfrentamiento bélico, por lo que apeló a la intervención de otros países de la región como Brasil, Chile, Argentina y Estados Unidos para solucionar el conflicto de forma diplomática.

Para la fecha, Estados Unidos ya estaba involucrado en la guerra, después del ataque japonés a Pearl Harbor de diciembre de 1941. Como respuesta, organizó un frente unido de los países del hemisferio durante las Conferencias de Panamá, en octubre de 1939, y las Conferencias de La Habana, en julio de 1940. Desde la perspectiva estadounidense, el conflicto ecuatoriano-peruano amenazaba la alianza de solidaridad hemisférica, por lo que su mayor interés era resolver rápidamente la cuestión limítrofe.

Durante la presidencia de Carlos Arroyo del Río, el 29 de enero de 1942, el Canciller Julio Donoso Tobar firmó el Protocolo de Paz, Amistad y Límites de Río de Janeiro, en el que el Ecuador cedió al Perú más de 56.000 kilómetros cuadrados, el equivalente a casi la mitad de su territorio. Sin lugar a dudas, esta fue la consecuencia
[11] Los primeros escritos relacionados con el cine en la prensa gráfica ecuatoriana fueron totalmente publicitarios. Wilma Granda, Cine Silente en Ecuador (Quito, Ed. Casa de la Cultura Ecuatoriana - Cinemateca Nacional, 1995), p. 44.

[12] Por el trabajo de archivo realizado durante alrededor de tres meses, agradezco la colaboración de Vanessa Álvarez, máster de la Facultad Latinoamérica de Ciencias Sociales (FLACSO) con sede Ecuador, dedicada al archivo de la ciudad de Guayaquil, y a la voluntad del Padre Jesuita Francisco Piña, Director General de la Hemeroteca Aurelio Espinosa Pólit.

[13] Milton Luna, Aula del siglo XXI: Historia y biografias del Ecuador (Quito, Cultural S.A., 2001), p. 120. 


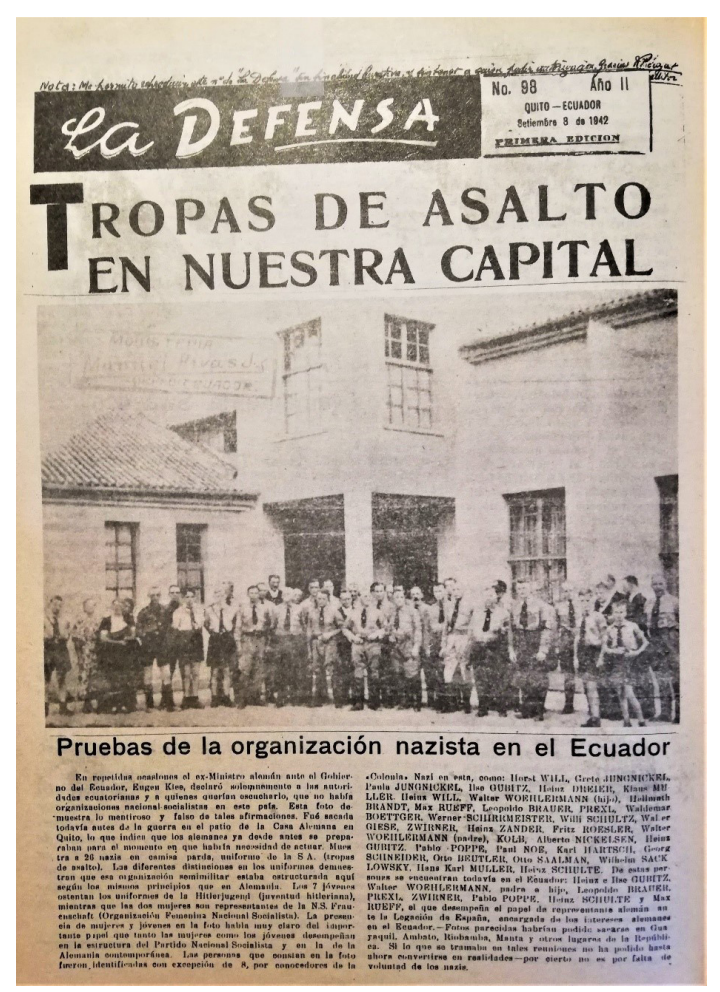

Diario La Defensa (no 98, 8 de septiembre de 1942, Quito-Ecuador).

[14] Piloto veterano de la Primera Guerra Mundial.

[15] George Lauderbaugh, Estados Unidos y Ecuador durante la Segunda Guerra Mundial: conflicto y convergencia (Quito, FLACSO Sede Ecuador, 2009), p. 267.

[16] George Lauderbaugh, Estados Unidos y Ecuador, p. 282.

[17] Exponentes como: Irving Hauptmann, llegado al país en 1931 y excapitán del ejército austriaco, conocido en el país como el Dr. Alfredo Enrique Cuhne. Fue consejero personal del presidente ecuatoriano Federico Páez (19351937). Walter Giese, coordinador nacional del partido nazi ecuatoriano, fue exjefe de la Gestapo. El cónsul alemán Bruckmann, también director de operaciones de la Compañía de Químicos Bayer en Ecuador.

[18] Julio Tobar Donoso, Informe a la Nación del ministro de Relaciones (Quito, Imprenta del Ministerio de Gobierno, 1941), p. 121. cana. más significativa de la Segunda Guerra Mundial para Ecuador.

La influencia del nacionalsocialismo alemán se enfocó en la comunidad de migrantes alemanes que llegaron al Ecuador después de la crisis de 1929 y que se organizaron alrededor del Colegio Alemán, del Club Social Alemán y de la aerolínea Sociedad Ecuatoriana de Transportes Aéreos (SEDTA), fundada por Fritz Hammer ${ }^{14}$, empresa de transporte para pasajeros y carga entre las ciudades más grandes del país - Quito, Guayaquil y Cuenca-.

La organización nazi ecuatoriana estuvo totalmente estructurada en 1940, contando con cincuenta y ocho miembros - de los cuatro mil inmigrantes alemanes que estaban registrados en $1937^{15}$ - y funcionaba con la misma estructura que el partido nazi alemán; tenía la División de Inteligencia, la de Hacienda, Comandancia de la Fuerza Aérea, Divisiones de las SA y las SS. La sección de Partmus incluía a la Asociación de Voluntarios, el Frente del Trabajo, la Juventud de Hitler, el Colegio Alemán y la Unidad de Prensa y Propaganda, unidad ejecutada por la agencia noticiosa Transocean, que se encargaba de difundir la versión alemana de la guerra en los medios de comunicación ecuatorianos.

La principal estrategia de la agencia Transocean fue pagar a diarios locales para que publicaran noticias favorables a Alemania. De esta manera, buscaban influir en el gobierno ecuatoriano, oficiales del Ejército, empresas y ciudadanos notables. Si bien las noticias de Transocean se hicieron notar, no lograron mayor alcance debido a que los diarios más importantes del país - El Telégrafo en Guayaquil y El Comercio en Quito - no necesitaban de apoyo económico alguno, lo que les permitió mantener una posición neutral con respecto a lo que sucedía en Europa. No obstante, algunos medios de prensa más pequeños accedieron a transmitir información pagada por Transocean, en especial el diario El Universo, el segundo diario de mayor circulación en Guayaquil, que fue descrito por la Legación estadounidense como «agresivamente pronazi» ${ }^{16}$. Asimismo, se incluyen publicaciones en los periódicos quiteños: El Día, El Debate, Vida Obrera y Regenerador, los cuales emitieron noticias pronazis y propaganda antiameri-

La influencia del movimiento nazi ecuatoriano y de las estratégicas conexiones de sus miembros con políticos e intelectuales ${ }^{17}$ provocaron una creciente simpatía, principalmente, en un círculo de intelectuales de extrema derecha como: Augusto Jácome; Jorge Luna Yépez - fundador del partido Acción Revolucionaria Nacionalista Ecuatoriana (ARNE) en 1942-; Julio Tobar Donoso, diplomático y canciller, que apoyó abiertamente al régimen nazi durante su gestión e incluso declaró que la generosidad del Ecuador para acoger refugiados debía ser recelosa con la comunidad semita, porque «...llegarían a formar una minoría racial y religiosa, absolutamente inadmisible, y construir para mañana un serio problema» ${ }^{18}$; Rafael Pino Roca, poeta y diplomático que contribuyó activamente al establecimiento de relaciones diplomáticas entre Ecuador y Alemania. 


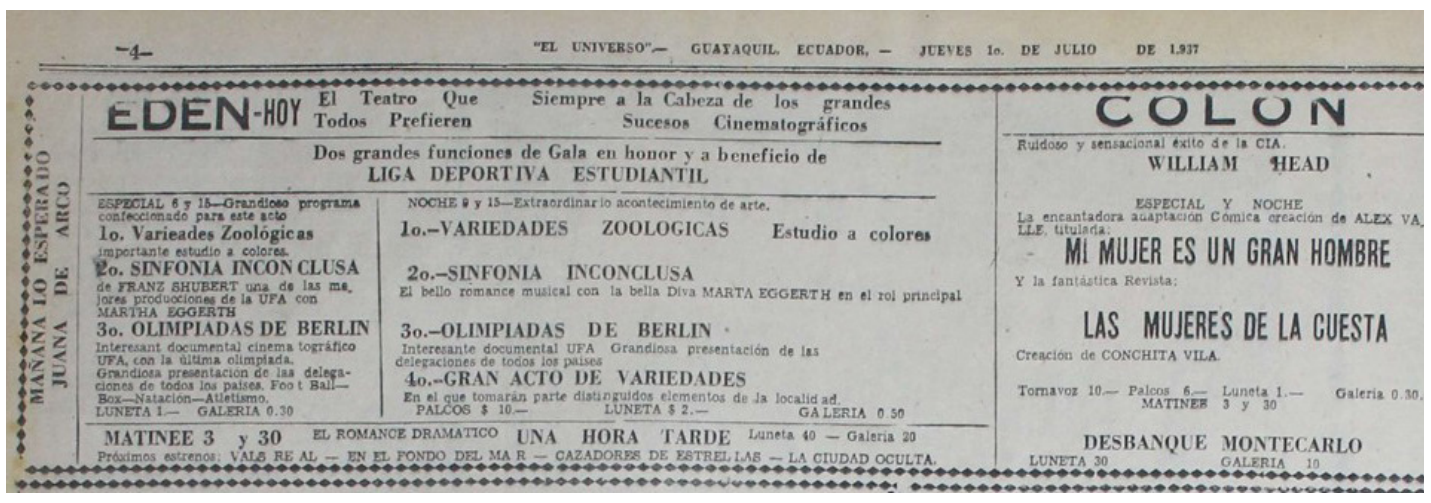

El primero de julio se presentó, en el Teatro Edén en la ciudad de Guayaquil, un fragmento del documental Olimpiadas de Berlín que mostraba las presentaciones de las delegaciones participantes en Football, Box, Natación y Atletismo. El documental completo Olimpiadas de Berlín (Olympia 1. Teil - Fest der Völker y Olympia 2. Teil - Fest der Schönheit, 1938) de Leni Riefenstahl no llegó a estrenarse en Ecuador durante el tiempo abarcado en esta investigación. Fuente: Diario El Telégrafo, №. 6.158, 1 de julio de 1937, Guayaquil-Ecuador..

Del mismo modo, hubo gobiernos ecuatorianos sucedidos a partir de 1933 - año en el que Hitler sube al poder como Canciller- que simpatizaron con el régimen nazi: el gobierno del general Alberto Enríquez Gallo (1937-1938) ${ }^{19}$, el de Aurelio Mosquera Narváez ${ }^{20}$ (1938-1939) y el de Carlos Alberto Arroyo del Río ${ }^{21}$ (19391944).

De forma paralela, surgió en el país un grupo de ciudadanos críticos hacia gobiernos «totalitarios» —el fascismo italiano, el nazismo alemán y el falangismo español- Como respuesta a la visibilización y al crecimiento paulatino del movimiento nazi ecuatoriano, y después de la propia experiencia de gobiernos coercitivos, un conjunto de migrantes alemanes contrarios al nazismo, parte de la colectividad judía e intelectuales de izquierda ecuatorianos organizaron un frente antitotalitario conocido en 1943 como el Movimiento Antifascista del Ecuador a cargo de Raymond Mériguet, inmigrante francés y miembro del Partido Comunista Francés que residió en Quito desde 1936, después de casarse con Nela Martínez, feminista ecuatoriana que conoció en París años antes.

Es preciso mencionar la importancia que tuvo la comunidad migrante judía en la lucha de organizaciones locales en contra del nazismo o de otros regímenes totalitarios, ya fueran internacionales o locales, ya que hicieron públicos los casos de persecución por motivos religiosos o raciales. La colectividad judía en el Ecuador se conformó gracias a las medidas migratorias adoptadas en 1935 por el presidente José María Velasco Ibarra que integraron varias «ventajas» a la población perseguida de origen judío, como la entrega de 485.000 hectáreas en diversas zonas del país, la excepción de impuestos a los beneficiarios durante tres años y transporte gratuito hacia el interior del país. Lamentablemente, las tierras concedidas estaban lejos de los centros urbanos y no se contemplaron las condiciones climáticas extremas que no se adaptaban al perfil de los beneficiarios, mayoritariamente, profesionales o comerciantes con poca o nula experiencia de trabajo agrícola ${ }^{22}$. Los beneficiarios se mudaron paulatinamente a los centros urbanos y se dedicaron a actividades comerciales o financieras, algo que despertó malestar en una parte de la sociedad ecuatoriana, en su mayoría comerciantes y políticos simpatizantes del nazismo.

[19] Mantuvo un discurso antiestadounidense y a la vez antisoviético.

[20] Fue fuertemente coercitivo al detener o impedir marchas y protestas sociales en contra de su mandato.

[21] Prohibió la realización de asambleas públicas para prevenir el fortalecimiento de colectivos ciudadanos que defendían la lucha contra gobiernos autoritarios y represivos.

[22] Emiliano Gil y Antonio Canela, La migración europea al Ecuador (1935-1955), p. 221. 
[23] Publicado por primera vez en 1940, tuvo una duración de 6 años.

[24] María Luise Kreuter, ¿Dónde queda el Ecuador? Exilio en un país desconocido desde 1938 hasta finales de los años cincuenta (Ecuador, Abya-Yala, 1997), p. 18 .

[25] Diario La Defensa, n. ${ }^{\circ} 98$, septiembre 8 de 1942, p. 1.

[26] Jenny Estrada, Segunda Guerra Mundial, lista negra en Ecuador (Quito, Ed. Cámara Ecuatoriana del Libro, 2006) p. 148.

[27] Fundado en 1942 imprimió treinta y seis números de denuncia contra el movimiento nazi ecuatoriano. El diario publicó su último número en julio de 1944.
La movilidad y adaptabilidad de la comunidad migrante judía permitió la construcción de relaciones con intelectuales de izquierda, lo que significó el fortalecimiento discursivo del Movimiento. Además, la inserción de judíos en medios de prensa locales aportó, indudablemente, a mantener el pensamiento crítico hacia regímenes autoritarios.

El Movimiento Antifascista del Ecuador tuvo dos frentes en su estrategia comunicativa: el periódico La Defensa ${ }^{23}$ y Antinazi. El primero estaba integrado mayoritariamente por intelectuales judíos residentes en Quito, como el jefe de ventas Arthur Eichler, berlinés socialista que huyó de Alemania como «combatiente ilegal» contra el nazismo. La redacción del periódico estaba a cargo inmigrantes judíos como Mijail Nerumenko y Wenzel Goldbaum, que ejerció como profesor de derecho en la Universidad Central del Ecuador ${ }^{24}$.

El mayor expositor de La Defensa fue el austriaco Benjamín Weiser Varon (Benno Weiser). Llegado al país en 1938, escribió para El Comercio y Últimas Noticias sobre las crónicas de la Guerra bajo el seudónimo de «Bobby» o «Próspero», respectivamente. En sus artículos, se encargó de denunciar a varios nazis que ocupaban altos cargos en el gobierno ecuatoriano y reveló los nombres completos de los miembros del movimiento nazi en el país.

En el número 98 de La Defensa se publicó un artículo titulado «TROPAS DE ASALTO EN NUESTRA CAPITAL $»^{25}$, que mostró fotos de alemanes y ecuatorianos en el patio de la embajada germana mientras hacían el saludo nazi, vestían camisas pardas y portaban brazaletes con esvásticas. Los nombres fueron incluidos en la lista negra ${ }^{26}$ de Estados Unidos, bajo la cual se gestionaron deportaciones de alemanes que simpatizaran con el régimen nazi después de 1941.

De forma paralela, el diario Antinazi ${ }^{27}$ se centró en difundir la crítica situación de Europa a causa de la Guerra, denunció el creciente antisemitismo del régimen hitleriano, las actividades nazis en el Ecuador, el aparecimiento de una rama local de la falange española y defendió la importancia de valores democráticos ante gobiernos coercitivos. Antinazi ayudó a que distintas secciones del Movimiento se crearan en

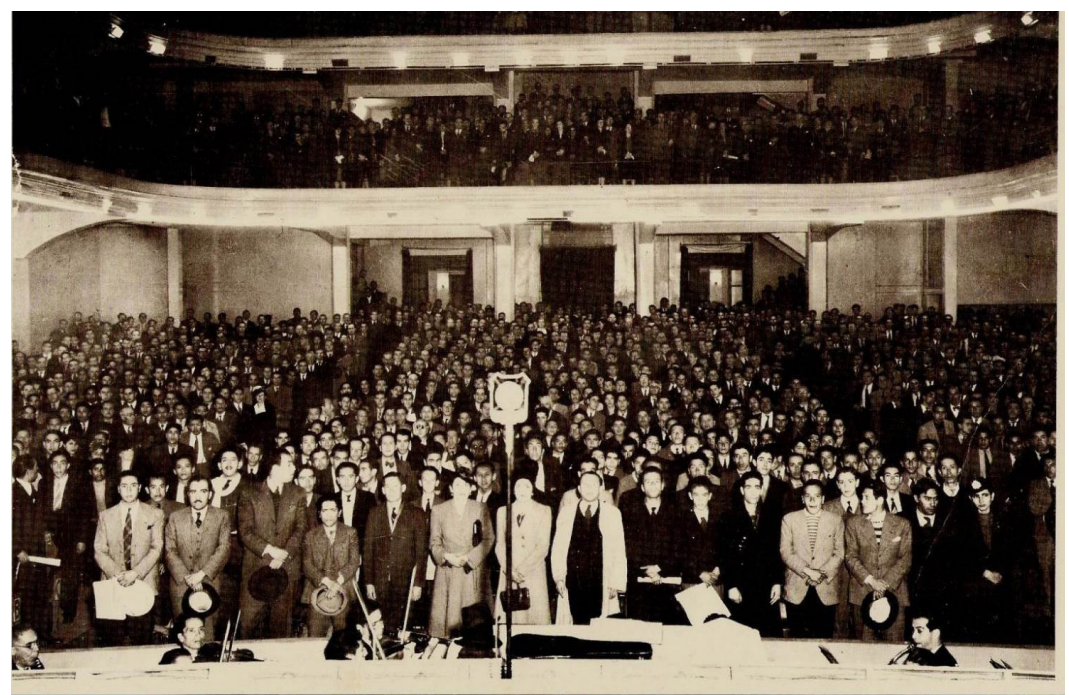

Reunión antinazi en el Teatro Capitol el 11 de febrero de 1943. Fuente: Diario Antinazi. 
Guayaquil, Cuenca, Ambato, etc., y posicionó al Movimiento como espacio de reunión para la lucha contra gobiernos totalitarios, incorporando en sus filas a dirigentes liberales, radicales socialistas, comunistas locales, una parte de la comunidad judía ecuatoriana, alemana ecuatoriana y líderes indígenas ${ }^{28}$.

El 11 de febrero de 1943 el Movimiento Antifascista del Ecuador organizó una concentración en el Teatro Capitol para conmemorar las victorias de Stalingrado y Trípoli. Asistieron al evento algunas delegaciones internacionales y representantes del cuerpo diplomático, calculando una convocatoria de cuatro mil personas. Su alcance provocó que, un día después, el presidente Arroyo del Río prohibiera la realización de asambleas públicas que no contaran con una autorización previa.
[28] Como Mériguet, Joaquín Gallegos Lara, Enrique Gil Gilbert, Nela Martínez, Manuel Agustín Aguirre, Manuel Quintanilla, Efrén Jurado López y Raúl Clemente Huerta, habiendo sido uno de los más destacados el líder indígena Jesús Gualavisí, quien de hecho conformó un comité antifascista en su comuna de Juan Montalvo, en el Cantón Cayambe.

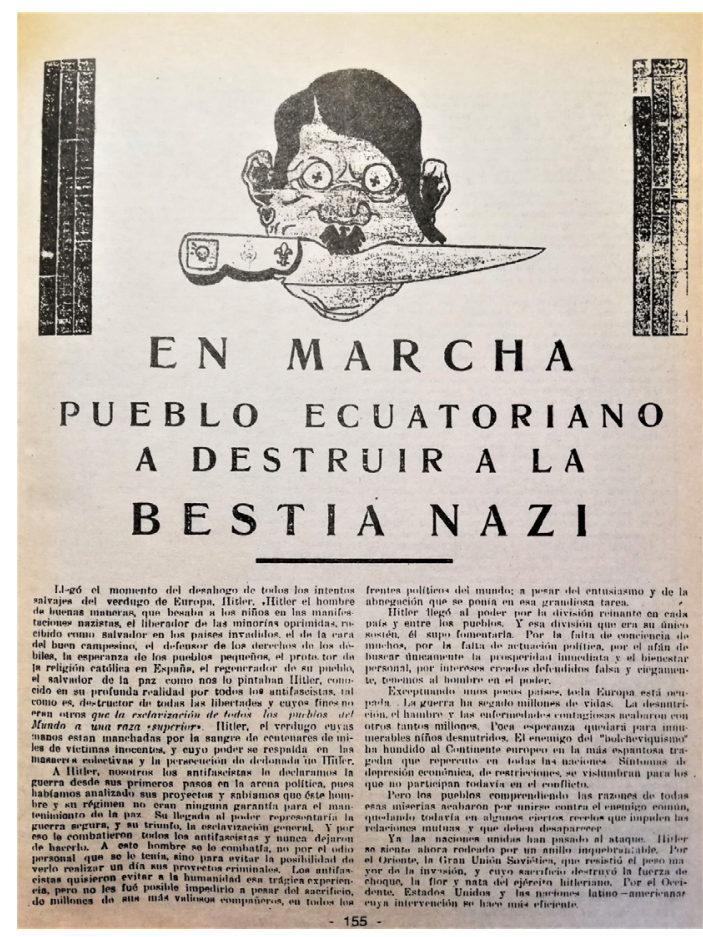

Diario Antinazi (no 13, 21 de noviembre de 1942, p.9).

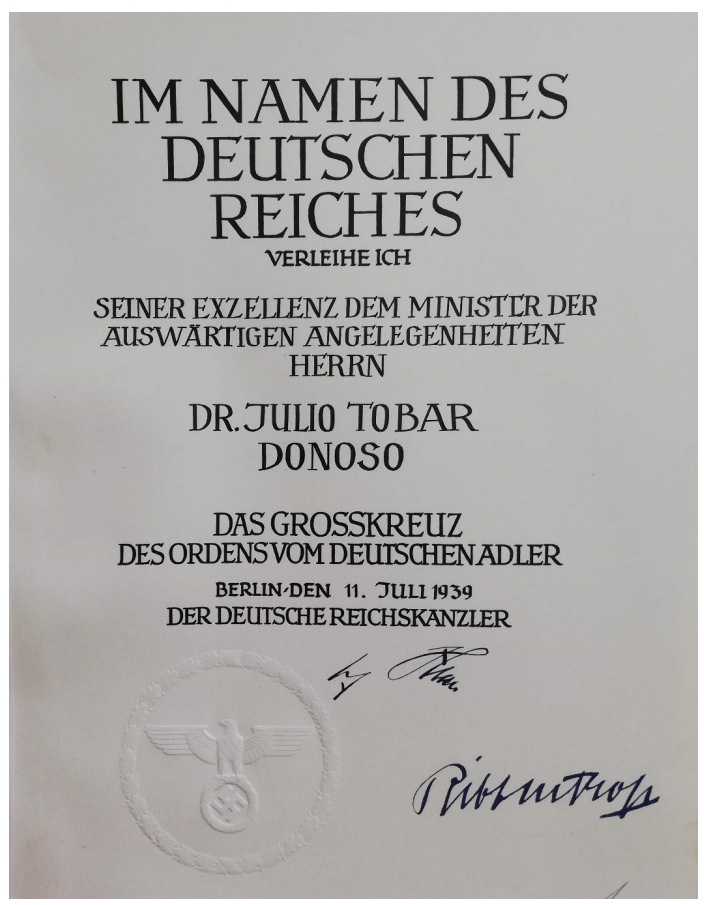

Fotografía de la Hemeroteca de la Biblioteca Ecuatoriana Aurelio Espinosa Pólit (Quito).

\section{EI desarrollo del cine en el Ecuador}

La llegada del cinematógrafo en 1910 permitió la creación de las primeras distribuidoras y productoras nacionales: Ambos Mundos, Excelsior y América, las cuales traían, principalmente, películas francesas, mexicanas y estadounidenses. La apertura del Canal de Panamá en 1914 facilitó la importación de filmes e infraestructura para la construcción de salas de cine privadas. Durante el mismo año, se construyeron en Quito el Teatro-Cine Variedades, el Cine Popular, equipado con cuadrilátero para boxeo y pista de patinaje, el Cine Puerta del Sol y el Royal Edén, las cuatro salas que conformaban una cadena de exhibición perteneciente al empresario Jorge Cordobés ${ }^{29}$.

La diferencia entre la cantidad de salas de exhibición en Quito y Guayaquil fue bastante significativa. Mientras que Quito contaba con cuatro salas, Guaya-
[29] En esta investigación no se encontró información precisa sobre el equipamiento de las demás salas. 
quil tenía veinte locales, entre ellos: Parisiana (1920), con capacidad para 1600 personas, Ideal (1922), equipado con 1700 butacas, Edén, para 400 personas, Olmedo (1910), con capacidad para 1600 personas, Frontón Bety Jai (1914), De las Peñas, Montalvo, Carpa del Malecón (1918), Quito, Bolívar, Victoria (1920), Vinces y Popular (1921), Chile (1923), Ecuador (1924), Enrique Valdez de Milagro y Ayacucho (1925), Sociedad General de Empleados (1926), etc. ${ }^{30}$ La diferencia se debía principalmente a que Guayaquil duplicaba la población de Quito y cada empresa exhibidora ubicada en Guayaquil disponía de su propio local para las proyecciones.

Durante los años veinte, el cine norteamericano conquistó la industria cinematográfica latinoamericana. Según Georges Sadoul, el cine hollywoodense ocupó del $60 \%$ al $90 \%$ de los programas en los mercados sudamericanos ${ }^{31}$. Durante 1923, el avance del cine estadounidense se evidenció con la firma de contratos de exhibición de varias empresas ecuatorianas con productoras estadounidenses como: Metro Goldwyng Mayer, Fox Pathé de New York, Eclair y Warner Bros ${ }^{32}$.

El cine se instauró como una práctica común en las ciudades y los diarios locales tuvieron que incorporar segmentos dedicados al cine: el diario El Telégrafo creó la columna «Teatros y Cinemas» y El Comercio publicaba la columna «Empresas de Teatros y Cinemas de Quito», que proporcionaban información sobre los programas y los costos de las películas, aunque no publicaban reseñas ni críticas de las mismas ${ }^{33}$.

En 1933 se inauguró uno de los teatros más famosos y concurridos de Quito, el Teatro Bolívar. Era — hasta entonces - el más grande del Ecuador, contaba con 2.500 butacas, estilo norteamericano formado por dos secciones: platea baja con 1.000 lunetas y superior con 850,30 palcos y 600 asientos $^{34}$. La apertura del Teatro Bolívar fue significativa no solo por la calidad de películas que fueron estrenadas en él, sino porque provocó la proliferación de nuevas salas en Quito como el Atahualpa, Granada, Bolívar, Cumandá, Hollywood, México y el Colón. No obstante, los cines México, Granada y Hollywood se dedicaron únicamente a la proyección de películas para adultos.

A pesar de que las salas de cine tuvieron una época de proliferación significativa, las cadenas de distribución y exhibición estaban concentradas en el cine norteamericano, mexicano y argentino. De igual forma, se ubicaban únicamente en Guayaquil y Quito restringiendo la accesibilidad al cinematógrafo a los poblados rurales o a las ciudades más alejadas de estos grandes centros urbanos.

\section{El cine alemán y de propaganda nazi en el Ecuador}

Durante los años treinta y la Segunda Guerra Mundial, la asistencia al cine era una práctica frecuente en las grandes ciudades del Ecuador, donde las salas de cine estaban totalmente equipadas y contaban con una programación cambiante que trataba de mantenerse lo más actualizada posible.

A partir del registro de los diarios de la época publicados en las ciudades de Quito y de Guayaquil, se verificó que, en el periodo comprendido entre 1935 y 1941, se estrenaron en el Ecuador cuarenta y dos películas de producción alemana. De estos títulos, seis filmes constan como películas prohibidas en las listas nombradas anteriormente. De los cuarenta y dos estrenos germánicos, treinta y un filmes fueron proyectados en Guayaquil y veinticuatro en Quito:
[30] Municipio de Guayaquil, Álbum guía de la ciudad de Guayaquil (Guayaquil, Imprenta y Talleres Municipales, 1929), p.24.

[31] Georges Sadoul, Historia del Cine Mundial (México, Siglo XXI, 1980) p. 137.

[32] Wilma Granda, Cine Silente en Ecuador, p. 42.

[33] Cabe recalcar que el régimen nazi también controló las reseñas cinematográficas en Alemania y en territorios ocupados. En 1936 Goebbles exigió a los escritores que se limitaran a escribir reseñas descriptivas, lo que se asemejaba a material publicitario. Roel Vande Winkel y David Welch, Cinema and the Swastika, p.9.

[34] Wilma Granda, Cine Silente en Ecuador, p. 58. 
Tabla 1: Cantidad de películas alemanas estrenadas en el Ecuador por año.

\begin{tabular}{|c|c|}
\hline Año & Cantidad de películas \\
\hline 1935 & 2 \\
\hline 1936 & 6 \\
\hline 1937 & 9 \\
\hline 1938 & 8 \\
\hline 1939 & 6 \\
\hline 1940 & 9 \\
\hline 1941 & 2 \\
\hline Total: & $\mathbf{4 1}$ \\
\hline
\end{tabular}

*Elaboración propia.

La primera película fue Internado para señoritas ${ }^{35}$ de la productora alemana UFA, estrenada en Guayaquil en abril de 1935 en el teatro Victoria. Ese mismo año llegó a Quito la película Entre dos corazones (Zwischen zwei Herzen, 1934), dirigida por Herbert Selpin ${ }^{36}$, una comedia de la productora Terra Film que se estrenó en el cine Royal Edén. Proyectada asimismo en las carteleras del cine Variedades, la película tuvo pocos días de permanencia en sala ${ }^{37}$.

En 1936 se registraron seis películas que llegaron a estrenarse en las salas de cine en Guayaquil y Quito: Desfile de primavera (Frühjahrsparade, 1934), de Géza von

[35] No se encontró información relacionada al director del filme o al año de estreno.

[36] Director alemán de varias películas filmadas durante el régimen nazi. Tuvo problemas durante la filmación de la versión alemana de Titanic (1943) por declaraciones negativas sobre las fuerzas armadas unificadas de la Alemania Nazi (Wehrmacht). Fue encontrado muerto en su celda en agosto de 1942

[37] Desde el sábado 28 de diciembre hasta el 31 de diciembre de 1935.

[38] N. del E. Estrenada en España como Vuelan mis canciones.

[39] N. del E. Estrenada en España como Una Carmen rubia.

[40] N. del E. Estrenada en España como La princesa de la Zarda.

[41] La cinta llegaría a las salas de cine de Guayaquil en 1939.
Bólvary; La sinfonía inconclusa ${ }^{38}$ (Leise Flehen Meine Lieder, 1933), de Willi Forst; Carmen rubia ${ }^{39}$ (Die Blonde Carmen, 1935), de Viktor Jansen; Carnaval del amor (Karneval und Liebe, 1934), de Karl Lamac; La princesa de las Czardas ${ }^{40}$ (Die Czardasfürstin, 1934), de Georg Jacoby ${ }^{41}$, y Oro (Gold, 1934), de Karl Hartl. Las películas fueron proyectadas en cuatro salas de cine de la ciudad de Quito - El Teatro Bolívar, Teatro Variedades, Teatro Popular y Teatro Puertas del SolDe estas, la única que llegó a Guayaquil durante ese año fue el filme Desfile de primavera proyectada en el Teatro Olmedo. En 1940 se realizó un remake estadounidense de la misma película bajo la dirección de Henry Koster, que también llegó a Quito en 1941.

De estas películas destaca Oro, el único largometraje de ciencia ficción producido por UFA durante el régimen nazi. Trata la historia de un científico alemán que investiga la piedra filosofal para convertir el agua en oro, pero es asesinado por un aristócrata inglés que desea conquistar el mundo de las finanzas apropiándose del invento del científico. Este largometraje llegó un año más tarde a Guayaquil, estrenándose en el Teatro Colón y, si bien el filme fue censurado por el tratado militar de los países aliados después de la guerra debido

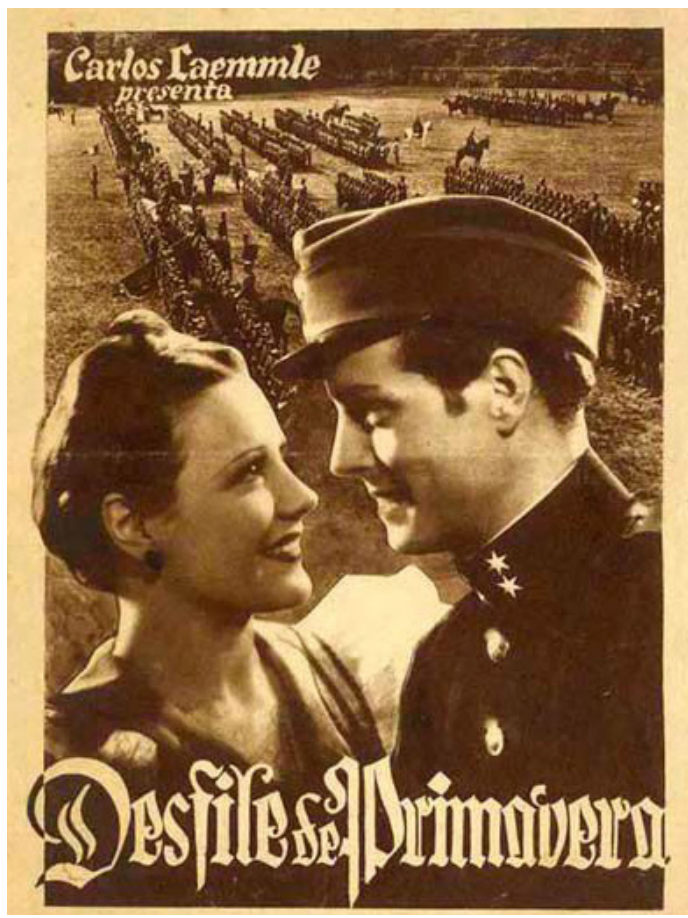

Cartel de Desfile de primavera (Frühjahrsparade, Géza von Bolváry, 1934). 
a la fuerte estigmatización de los personajes, actualmente no se encuentra dentro de las listas de películas prohibidas.

Para 1937 se registraron diez largometrajes germánicos: Ocho chicas en un bote (Acht Mädels im Boot, 1932), de Erich Waschneck; Vals Real (Königswalzer, 1934), de Herbert Maisch; Juana de Arco ${ }^{42}$ (Das Mädchen Johanna, 1935) de Gustav Ucicky; Barcarola (Barcarole, 1935) de Gerhard Lamprecht; Victor y Victoria ${ }^{43}$ (Viktor und Viktoria, 1933) de Reinhold Schünzel; La sinfonía inconclusa (Leise flehen meine Lieder, 1933) y estrenada durante el año anterior en Quito; Casta Diva ${ }^{44}$ (1935) de Carmine Gallone; El hijo perdido (Der verlorene Sohn, 1934), de Luis Trenker; Yo y la Emperatriz (Ich und die Kaiserin, 1933), de Friedrich Hollaender, y Un matrimonio inglés (Die englische Heirat, 1934) de Reinhold Schünzel. Cabe recalcar que, en este año se estrenaron la mayor cantidad de películas alemanas, principalmente en Guayaquil, y de las doce películas solo tres estuvieron en las salas quiteñas: Ocho chicas en un bote, Vals Real y Juana de Arco.

Los largometrajes Juana de Arco y El hijo perdido recibieron el reconocimiento del régimen nazi como «artísticamente valiosas» y con un «valor político especial» debido al nivel de propaganda que contienen ${ }^{45}$.

El filme Juana de Arco narra la historia de la joven campesina a los diecisiete años de edad y fue ambientada en la Francia del siglo xv. El filme tenía una fuerte ideología nacionalsocialista, razón por la cual su difusión fue controlada hasta 1945, año en el que fue transmitida únicamente en la Alemania ocupada por los Aliados. En 1967, fue integrada al listado de películas de propaganda nazi y, actualmente, está prohibida su difusión. Por otra parte, El hijo perdido retrata la vida de un joven alemán que migra a los Estados Unidos durante la Gran Depresión, pero, al llegar, se desilusiona por las falsas promesas de prosperidad y éxito de una sociedad corrupta $\mathrm{y}$, después de varias peripecias, decide regresar a su querida Alemania ${ }^{46}$.

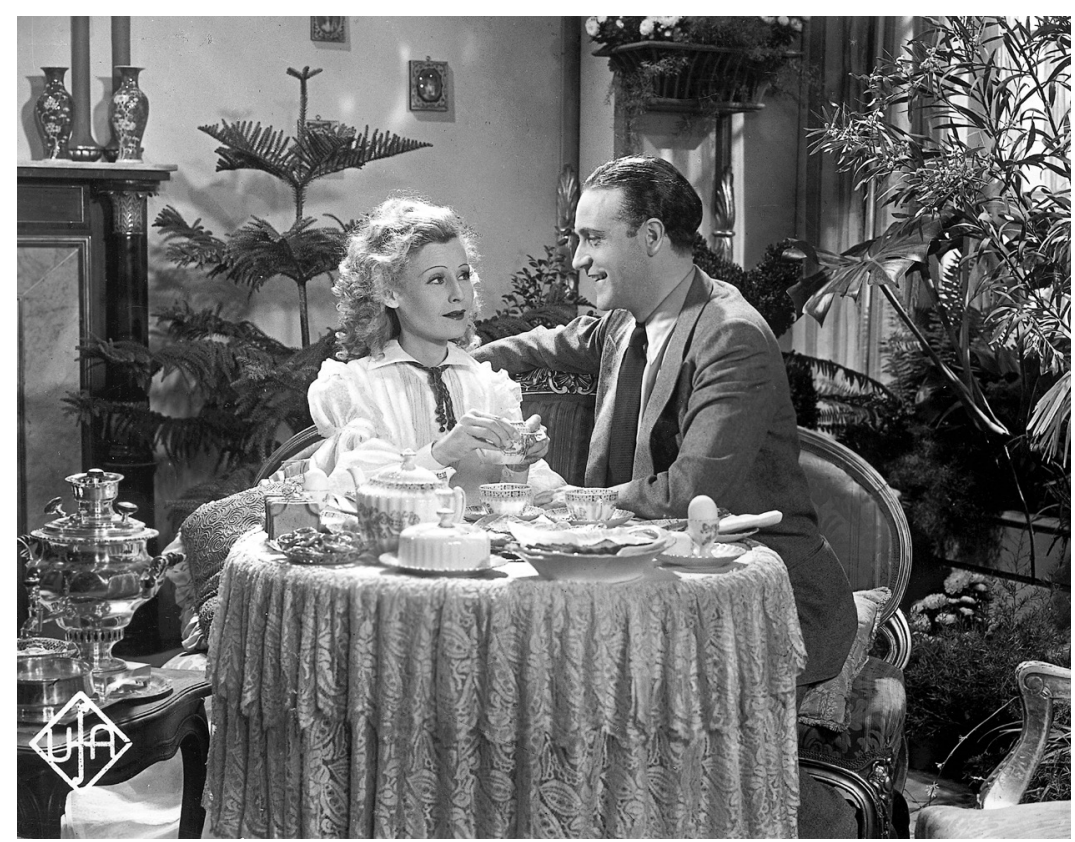

Fotograma de Rosas negras (Schwarze Rosen, Paul Martin, 1935).
[42] N. del E. Estrenada en España como Santa Juana de Arco.

[43] N. del E. Estrenada en España como El... es ella.

[44] Se conservó el título original en su estreno en Ecuador.

[45] En 1934 se creó la Ley de Cine (Reichslichtspielgesetz) que creó algunas categorías distintivas para las producciones germanas: Institucional (1920); Educación Nacional (1924); de Valor Político y Artístico (1933); de Especial Valor Político (1933); de Especial Valor Artístico (1933); Valor Político (1933); Valor Artístico (1933); Valor Cultural (1933); de Valor para la Juventud (1938); de Valor Nacional (1939); y Película de la Nación (1939). Las películas de valor político eran las que reflejaban los objetivos del Partido. Este título fue otorgado no solo a documentales como el Triunfo de la Voluntad (Triumph des Willens, Leni Riefenstahl, 1935), sino también a películas con un mensaje político, como la proeutanasia en la producción Yo Acuso (Ich klage an, Wolfgang Liebeneiner, 1941). La combinación de valor político y cultural significaba una calidad especial y un nivel alto de credibilidad. Las de valor artístico fueron entendidas desde la perspectiva cultural y fueron otorgadas solo a filmes prestigiosos y aquellos reservados a exportación. Roel Vande Winkel y David Welch, Cinema and the Swastika, p.6.

[46] Al finalizar la Guerra, este film fue prohibido por Alemania Occidental que la veía como antiamericana y también por la Alemania Oriental que la consideraba proamericana. 
Todas las cintas fueron proyectadas en el Teatro Edén y el Teatro Colón en Guayaquil. En Quito, se trasmitieron en los cines Bolívar, Variedades, Edén, Puertas del Sol y el Teatro Popular, con excepción del filme Ocho chicas en un bote que fue transmitido únicamente en el Teatro Variedades.

En 1938, proliferaron varios comercios de origen judío, ocasionando preocupación en los quiteños. Se fortaleció un discurso antisemita que sostenía que la competencia judía era desleal. Como respuesta, el presidente Alberto Enríquez Gallo dispuso, en un decreto emitido el 18 de enero de 1938:

La necesidad de garantizar a todos los ecuatorianos y extranjeros que se dedican a la agricultura y a la industria el fácil desarrollo de sus laboriosas actividades y evitar que extranjeros indeseables negocien esquivando las normas legales con grave detrimento para el desenvolvimiento nacional ${ }^{47}$.

Después del comunicado se estableció que todos aquellos inmigrantes judíos que no se dedicaran a la industria y a la agricultura debían salir del país en un plazo de treinta días ${ }^{48}$. Un mes después, en la presidencia de Aurelio Mosquera Narváez, se decretó la Ley de Extranjería, Extradición y Naturalización el 16 de febrero de 1938 que restringía la entrada de migrantes judíos a Ecuador a excepción de profesionales dedicados a la ciencia, arte o educación.

Para hacer efectiva la Ley, el canciller Tobar Donoso emitió un comunicado dirigido a cónsules ecuatorianos en Europa, en el que apelaba a restringir la emisión de visado al colectivo judío: «Por el porvenir ético, económico y moral de la Nación recomiendo a usted tomar las precaucione posibles y la máxima escrupulosidad al visar el pasaporte de un extranjero que perteneciese a esa raza». Además, se les exigía pruebas de solvencia económica y se prohibió emitir visas de turismo a judíos.
[47] Registro oficial 1938.

[48] Pablo Mériguet, Historia del Movimiento Antifascista del Ecuador (1941-1944) (Quito, Universidad Católica del Ecuador PUCE, 2016), p. 124.

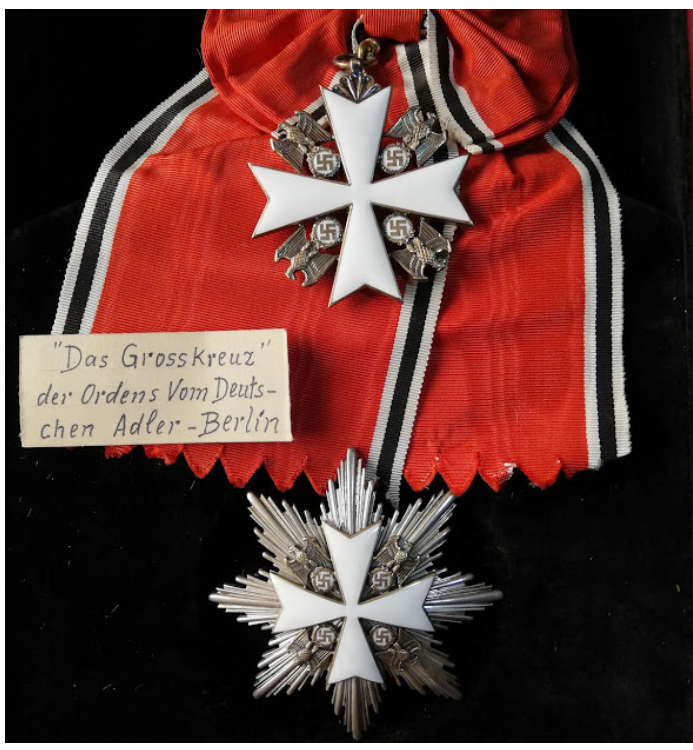

Fotografía de la Hemeroteca de la Biblioteca Ecuatoriana Aurelio Espinosa Pólit (Quito). Condecoración de «La gran cruz de la Orden del Águila alemana» otorgada a Julio Tobar Donoso en 1939.

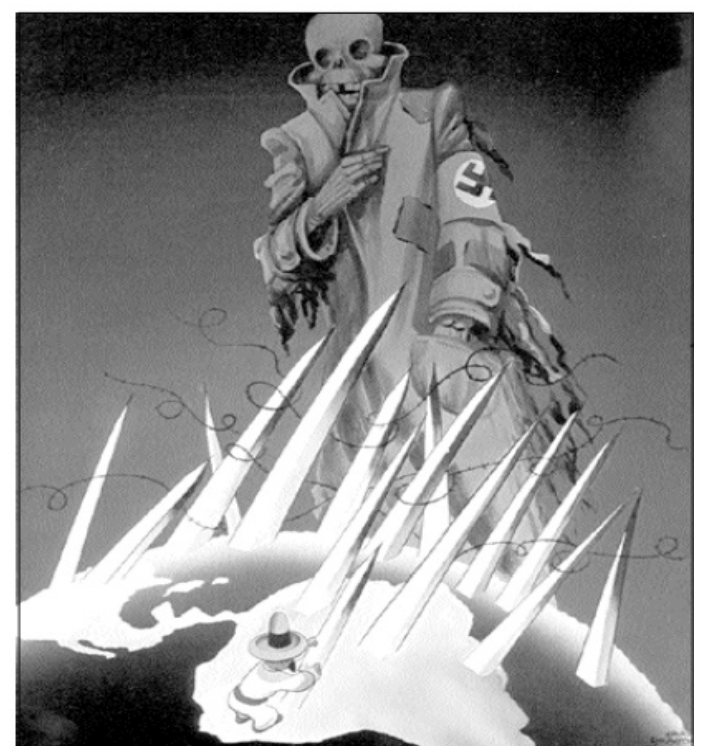

Fuente: George Lauderbaugh, Estados Unidos y Ecuador durante la Segunda Guerra Mundial: conflicto y convergencia, en Beatriz Zepeda (comp.), Ecuador: relaciones internacionales a la luz del bicentenario (Quito, FLACSO Sede Ecuador, 2009). 
[49] N. del E. Estrenada en España como Valses de Neva.

[50] Se dice que el mismo Benito Mussolini participó en la escritura del guion de la película y dio instrucciones a los actores sobre cómo interpretar a Napoleón. $N$ del E. Estrenada en España como 100 dias.

[51] N. del E. Estrenada en España como El Zarewistch.

[52] La cinta llegaría a las salas de Guayaquil el siguiente año (1939).

[53] No se encontró información detallada sobre este filme.
Este año, el Ecuador alcanzaría la cúspide de las relaciones diplomáticas con Alemania por la labor de Julio Tobar Donoso como Canciller que, un año más tarde, sería reconocido con la Gran Cruz de la Orden del Águila Alemana otorgada por el régimen nazi.

Las políticas antisemitas promovidas por el gobierno ecuatoriano acrecentaron la confianza suficiente para que el movimiento nazi ecuatoriano hiciera su primera demostración pública en Quito, a razón de la caída de un avión Junkers52 de la compañía SEDTA, aerolínea comercial formada y controlada por alemanes en Ecuador, en el que organizó un homenaje fúnebre a los pilotos fallecidos, ofreció arreglos florales y realizó el saludo oficial nazi.

Durante este periodo, se estrenaron ocho filmes alemanes, mayoritariamente en Quito: Rosas negras (Schwarze Rosen, 1935), de Paul Martin; Madrecita (Kleine Mutti, 1935), de Herman Kosterlitz; Noches de San Petersburgo ${ }^{49}$ (Petersburger Nächte, 1935), de E.W. Emo; Los 100 días de Napoleón ${ }^{50}$ (Hundert Tage, 1935), de Franz Wenzler; El hijo del Zar ${ }^{51}$ (Der Zarewitsch, 1933), de Víctor Janson; El Acorazado Sebastopol (Weiße Sklaven, 1936), de Karl Anton; Miguel Strogoff o El correo del Zar (Michel Strogoff, 1936), de Richard Eichberg52, y Catalina ${ }^{53}$. Las únicas películas que llegaron a las salas de cine guayaquileñas fueron Rosas negras y Madrecita — transmitidas en el Teatro Edén — y Noches de San Petersburgo — proyectada en el Teatro Olmedo. En Quito, las películas fueron emitidas en El Teatro Bolívar, Variedades, Colón, Puertas del Sol y Teatro Popular.

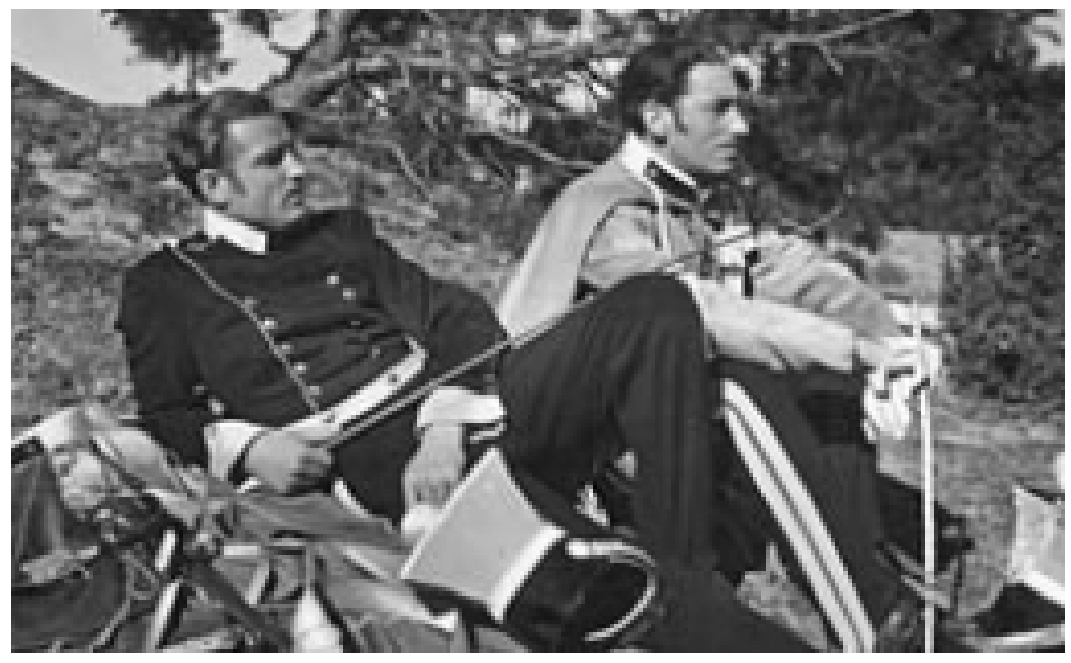

Fotograma de Los Húsares de la muerte (Ritt in die Freiheit, Karl Hartl, 1937).

De estos largometrajes, Rosas negras y El Acorazado Sebastopol fueron censuradas después del término de la guerra, a fin de evitar la difusión pública de propaganda nazi. Rosas negras es ambientada en Finlandia, cuando todavía pertenecía al Imperio Ruso. Relata la historia de una bailarina rusa que ayuda a una compañera finlandesa a luchar contra agentes zaristas. La bailarina revolucionaria acaba dando la vida por su amado. La película está registrada dentro de los filmes prohibidos de propaganda nacionalsocialista. Por otro lado, El Acorazado Sebastopol presenta una historia de amor que se desarrolla en un crucero precisamente en el momento en el que estalla la Revolución Rusa, provocando que los marineros se amotinen y tomen a la prota- 
gonista como prisionera, liderados por quien había sido su criado. Esta cinta fue una imitación del largometraje El acorazado Potemkin (Bronenósets Potiomkin, 1926), dirigida por Seguéi M. Eisenstein ${ }^{54}$. Lo cierto es que, tanto en el aspecto técnico como en el artístico, la cinta fue un intento fallido de igualar a la obra cinematográfica rusa. En 1939 se estrenaron seis largometrajes alemanes: Dos mundos o La tragedia de una raza (Leutnant Bobby, der Teufelskerl, 1935), de Georg Jacoby; La Indómita ${ }^{55}$ (Die unmögliche Frau, 1936), de Johannes Meyer; Miguel Strogoff o El correo del Zar (1936) — cinta que ya había sido estrenada en Quito el año anterior-; La princesa de las Czardas (1934) — largometraje que también llegó primero a Quito durante 1936- Encantos de bohemia $^{56}$ (Zauber der Boheme, 1937), de Géza von Bólvary; Los Húsares de la muerte (Ritt in die Freiheit, 1937), de Karl Hartl; La princesa Turandot ${ }^{57}$ (Prinzessin Turandot, 1934), de Gerhard Lamprecht; y Tu eres mi felicidad (Du bist mein Glück, 1936), de Karl Heinz Martin. El filme Los Húsares de la muerte está clasificada como propaganda nacionalsocialista, si bien se puede encontrar la película en sus archivos, la fundación cuida recelosamente su difusión a través de proyecciones públicas seleccionadas.

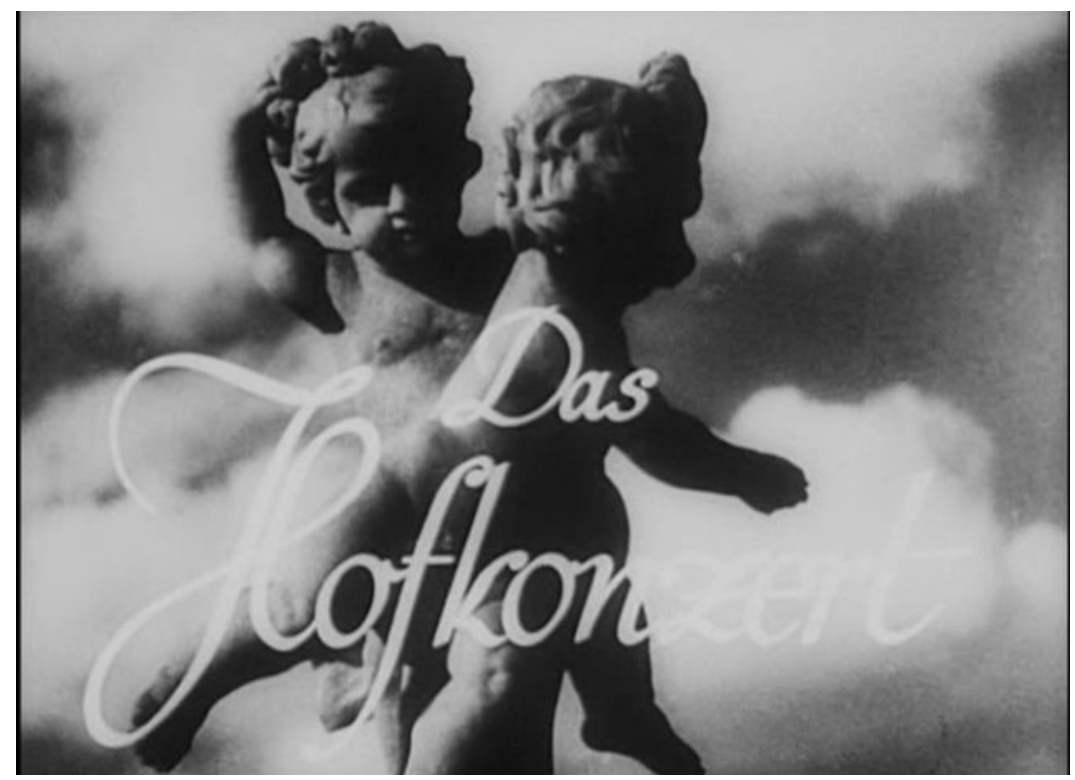

Fotograma de Ensueños (Das Hofkonzert, Douglas Sirk y Serge de Poligny, 1936).

En Guayaquil la cinta Dos mundos fue emitida únicamente en el Teatro Parisian, mientras que La Indómita, Miguel Strogoff y La princesa de las Czardas fueron proyectadas en el Teatro Edén. En Quito, Encantos de bohemia se pasó en los programas del Teatro Bolívar, Puertas del Sol y el Teatro Colón; Los Húsares de la muerte y La princesa Turandot fueron transmitidas en el Teatro Bolívar, Variedades, Cumandá, Teatro Popular y Teatro Colón, mientras que Tu eres mi felicidad solo se pasó en tres de los teatros anteriormente mencionados - Teatro Bolívar, Variedades y Cumandá-.

El 1 de octubre de 1940 se discutió en el Congreso Nacional sobre la penetración de ideología nacionalsocialista en el Ecuador por el descubrimiento de una emisora clandestina que estaba a cargo de la Compañía Otto Wolfe, presidida por Otto
[54] La película reproduce el motín ocurrido en el acorazado Potemkin en 1905, cuando la tripulación se rebeló contra los oficiales de la armada zarista. Es considerada una de las mejores películas en la historia del cine.

[55] N. del E. Estrenada en España como Lo que puede un hombre.

[56] N. del E. Estrenada en España como Vida de la Boheme.

[57] N. del E. Estrenada en España como Turandot, princesa de China. 
[58] El Comercio, n. ${ }^{\circ} 12.699,1$ de octubre de 1940, p. 5.

[59] Por ejemplo: el Partido Integralista en Brasil, las Camisas Doradas en México, el Partido Nazi en Costa Rica, Los Leopardos en Colombia, etc.

[60] En este artículo se utilizará la abreviatura.

[61] Luiz Nazario, «Nazi Film Politics in Brazil, 1933-42», en Roel Vande Winkel y David Welch (eds), Cinema and the Swastika, p. 94.

[62] Como se mencionó anteriormente, las empresas exhibidoras se concentraron en las grandes ciudades del país, restringiendo el acceso al cinematógrafo a las poblaciones rurales y más alejadas de centros urbanos.

[63] George Lauderbaugh, Estados Unidos y Ecuador durante la Segunda Guerra Mundial, p. 286.

[64] N. del E. Estrenada en España como La señorita del avión.

[65] N. del E. Estrenada en España como Concierto en la corte.

[66] N. del E. Estrenada en España como Una aventura en Polonia.

[67] El titulo original de Truxa se mantuvo en su estreno en Ecuador. [N. del E. Estrenada en España como Truxa y la bailarina.]

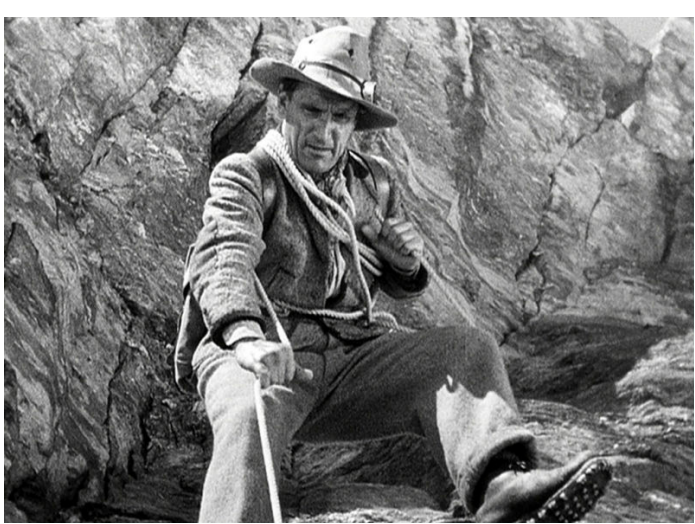

Fotograma de Der Berg ruft! (Louis Trenker,1938).. Sangolquí y Latacunga ${ }^{63}$.
Heinrich Carstanjen, alemán de nacimiento que luego se naturalizó ecuatoriano. La compañía tenía concesiones de petróleo y se sospechaba que la radio clandestina establecía contacto con submarinos alemanes. Además, se descubrieron ametralladoras dentro de las instalaciones del Colegio Alemán de Quito ${ }^{58}$.

Cabe recalcar que, para 1940, proliferaron varios colectivos pronazis en países latinoamericanos ${ }^{59}$. Estados Unidos iniciaría una de las campañas publicitarias más grandes en toda la región con el objetivo de neutralizar el avance del nazismo por medio de la Oficina para la Coordinación de Relaciones Comerciales y Culturales entre las Repúblicas Americanas, presidida por Nelson Rockefeller. En 1941 fue rebautizada como la Oficina de Asuntos Interamericanos (OIAA) ${ }^{60}$. La institución tenía Comités Coordinadores locales que impulsaron no solo propaganda antinazi, sino una fuerte campaña proamericana, en la que Estados Unidos era el principal promotor de los valores democráticos en el mundo.

La OIAA trabajaba con asociaciones locales en actividades de entretenimiento, arte, ciencia, educación, turismo, radio, prensa y cine. Contaron con el apoyo de actores y productores como Orson Welles, John Ford, Walt Disney, Gregg Toland, Henry Fonda, Errol Flynn y Douglas Fairbank $\mathrm{Jr}^{61}$. En el Ecuador, la OIAA distribuyó 249.000 afiches que presentaban «la amenaza nazi» en la región en un lenguaje sencillo y fueron distribuidos principalmente en centros educativos y culturales. En uno de los afiches se mostraba a Hitler a punto de destruir una iglesia, pero es interrumpido por un campesino.

El programa más exitoso de la OIAA consistió en la proyección de películas en todo el país ${ }^{62}$. Según reportes de 1943, se proyectaron en total ciento once películas, incluyendo veintisiete carretes de noticias, treinta sobre los esfuerzos de guerra, veintiséis de información y veintiocho educativos que fueron vistas por alrededor de 250.000 ecuatorianos. Debido a que no existían salas de cine en las ciudades más pequeñas, el Comité Coordinador de la OIAA en Ecuador tuvo que improvisar la proyección de las películas en plazas públicas y escuelas en Guaranda, Salcedo, Pujilí,

En comparación con la fuerte campaña cinematográfica estadounidense, para el mismo año, se registraron nueve estrenos germánicos en Quito y Guayaquil. Las cintas estrenadas en Guayaquil fueron: Los Húsares de la muerte (que fue difundida en Quito el anterior año), Romance real ${ }^{64}$ (Die kleine und die große Liebe, 1938), de Josef von Báky; Ensueños ${ }^{65}$ (Das Hofkonzert, 1936), de Douglas Sirk y Serge de Poligny; El murciélago (Die Fledermaus, 1937), de Paul Verhoeven y Hans H. Zerlett; Patriotas (Patrioten, 1937), de Karl Ritter; y La golondrina cautiva (Zu neuen Ufern, 1937), de Detlef Sierck. Estos filmes fueron proyectados en el Teatro Olmedo, mientras que Tragedia en los Alpes (Der Berg ruft!, 1938), de Louis Trenker, y La patrulla de la muerte ${ }^{66}$ (Abenteuer eines jungen Herrn in Polen, 1937), de Gustav Fröhlich, fueron proyectadas en el Teatro Quito y en el Edén, respectivamente. En Quito se exhibieron: La Indómita - estrenada en Guayaquil durante el año anterior-, Truxa $(1937)^{67}$, de Hanns Zerlett, y iVolga, Volga! (Stjenka Rasin, 1936), de Alexandre Volkoff. Estas fueron las últimas películas germánicas que llegaron a Quito durante 
la Segunda Guerra Mundial.

Las películas Patriotas y Romance Real constan como películas de propaganda nazi, y su difusión es controlada por la Fundación F.W. Murnau. La película Patriotas relata la traición cometida hacia el oficial de aviación alemán que termina a la merced de un grupo de teatro en territorio francés. Por otro lado, la cinta Romance Real narra el romance entre una azafata que se enamora de un pasajero. El pasajero termina siendo un príncipe que ya está comprometido con otra mujer, pero, cuando el príncipe se entrera de la enfermedad de la azafata, renuncia a todo para terminar juntos.

Otro de los largometrajes que destaca es Tragedia en los Alpes. Trata sobre un montañista italiano que quiere ser el primer hombre en conquistar la cima de la montaña Matterhorn. Como la escalada es desafiante, acepta intentarlo con un alpinista británico, pero después de una intriga, los dos hombres intentan llegar a la meta el mismo día con diferentes equipos.

Mientras que Patriotas y Romance Real constan todavía como películas de propaganda, Tragedia en los Alpes fue reconocida por el régimen nazi como «artísticamente valiosa» y de un «valor político especial», aunque ya no está considerada como película de propaganda en ninguna de las listas consultadas.

En junio de 1941 el canciller Tobar Donoso prohibió la concesión de visados a judíos. La medida fue criticada fuertemente por los consulados de Estocolmo, Bremen, Hamburgo, Ginebra y Marsella, aunque la prohibición quedó sin legalidad en 1942, cuando Ecuador rompe definitivamente relaciones diplomáticas con Alemania, Italia y Japón y después de la renuncia formal de Tobar Donoso como canciller.

Después de la ruptura de relaciones diplomáticas con Alemania se estableció la «Lista Negra», bajo la cual se investigaron a alemanes identificados como nazis. Algunos salieron del país o se escondieron en lugares recónditos del Ecuador, pero la mayoría fue recluida y enviada a Crystal City, Texas, o a Cuenca ${ }^{68}$.

Durante este año, llegaron dos películas a Guayaquil: ;Volga, Volga!, estrenada en el Teatro Parisiana y exhibida en Quito el año anterior, y El soberano (Der Herrscher, 1937), de Veit Harlan, proyectada en el cine Olmedo. Esta película tuvo la premiación de mejor actuación para el actor principal (Emil Jannings) en el Festival de Venecia, evento creado por Mussolini como plataforma de la propaganda fascista. El filme relata la decisión del dueño de una fábrica de acero que decide desheredar a los suyos después de varias riñas familiares y entregar la fábrica al Estado.

Posteriormente a 1941, los programas de cine en Quito y Guayaquil demostraron una gran diversificación en sus contenidos, promocionando cine francés, cine inglés y estadounidense con mucha más fuerza, además del conocido cine argentino y mexicano.

Uno de los rasgos que se destacaron durante la investigación fue la forma en la que se publicitaban las películas alemanas en el Ecuador. Si bien funcionaba exclusivamente a través de los medios impresos, los diarios dedicaron grandes espacios publicitarios a estos largometrajes, especialmente si se trataban de operetas o musicales. La publicidad de los filmes era amplia y volcada a reconocer el nivel de producción que implicó el rodaje de los filmes. En este aspecto se destacaba toda película realizada por la productora alemana Universum Film Aktiensgesellschaft (UFA), la productora cinematográfica más importante del régimen de Hitler, a cargo de Joseph Goebbels como ministro para la Ilustración Pública y Propaganda durante todo el periodo de guerra (1933-1945).
[68] Daniel Kersffeld, Antinazi: Ecuador y el movimiento de lucha contra el nazismo durante la Segunda Guerra Mundial (Quito, Universidad Andina Simón Bolívar Sede Ecuador, 2015), p. 15. 
[69] En el archivo del diario $\mathrm{El}$ Telégrafo de Guayaquil no se encontró registro de espacios dedicados específicamente a la promoción de películas en general.

[70] El Comercio, n. ${ }^{\circ} 12.323,18$ de septiembre de 1939, p. 4.

[71] El Comercio, n. ${ }^{\circ} 12.149,4$ de abril de 1939, p. 4.

[72] El Comercio, n. ${ }^{\circ} 11.531,21$ de mayo de 1937, p. 5.

[73] El Comercio, 28 de octubre de 1938.

[74] Este largometraje está catalogado como material de propaganda nazi y su difusión se encuentra custodiada por la Fundación F.W. Murnau. Trata sobre las rebeliones polacas contra la dominación rusa y termina con la derrota de las tropas polacas que anhelan pacientemente el resurgimiento de su nación.

[75] El Comercio, n. ${ }^{\circ}$ 12.318, 23 de julio de 1939, p. 5.

[76] El Comercio, n. ${ }^{\circ} 11.286,9$ de enero de 1937 , p. 4

[77] El Comercio, n. ${ }^{\circ} 11.750,29$ de julio de 1938, p. 4.
La mayoría de las películas de propaganda nazi que llegaron al Ecuador lograron difundirse en el país porque llevaban el sello de la productora UFA como sinónimo de indiscutible calidad fílmica, y fue así como se promocionaron en la prensa gráfica de Quito ${ }^{69}$.

El filme La princesa de las Czardas fue promovido como «super joya musical» ${ }^{70}$, y de La sinfonía inconclusa se dijo: «La mejor película musical del año. El máximo triunfo de la cinematografía reconstructiva europea presentada por UFA $»^{71}$. Cuando Juana de Arco se estrenó en Quito, la propaganda decía: «Incomparable espectáculo histórico-dramático que ofrece la casa de los grandes films: UFA de Berlín» ${ }^{72}$. Lo mismo sucedió con Rosas Negras: «UFA—la gran filmadora europeanos ofrece una excelsa historia de amor, de política y preciosamente clásica de danza y música ${ }^{73}$.

La película Los Húsares de la muerte ${ }^{74}$, de argumento bélico, fue uno de los filmes alemanes más publicitados del año en la prensa gráfica quiteña. En páginas del diario El Comercio de Quito se encontraron varios anuncios ${ }^{75}$ que decían de la película:

«Pragmáticas páginas de la historia de Europa reviven con impresionantes matices en una grandiosa y espectacular super producción de la UFA.»

«Vienen los HUSARES!! ¡¡Osados y arrogantes destruyendo a su paso todos los obstáculos, su heroísmo marca en letras de sangre y hierro una brillante jornada en los anales épicos de la historia de la indomable nación polaca!!»

«La trágica visión de la guerra de Polonia de 1831. Llevada a la pantalla con la colaboración de los mejores actores de la UFA.»

La publicidad de los largometrajes alemanes estaba ligada a temas relacionados con la modernidad y la creciente modificación de los roles de género, especialmente sobre el comportamiento femenino en una época cambiante. Temas como qué debería importarles a las mujeres modernas, cuáles eran sus problemáticas o cómo una mujer moderna los afrontaba eran cuestiones que animaban al público a comprar el ticket.

Un ejemplo es la publicidad del filme Ocho chicas en un bote: «La película que plantea el inquietante problema de la mujer actual incapaz de eludir las asechanzas que la rodean en esta era de emancipación femenina ${ }^{7{ }^{6}}$ 》

La cinta Catalina fue promocionada aludiendo: «Preciosísima historia de una nueva Cenicienta alegre, jovial, soñadora! La más comprometedora de las escenas ${ }^{77}$ Desafortunadamente, no se encontró ninguna información que nos diera pistas sobre qué tipo de escena era, pero no cabe duda de que, en una sociedad conservadora como la ecuatoriana de la época, este tipo de propaganda haya suscitado interés en el filme.

\section{Conclusiones}

Esta investigación devela la lucha ideológica-política que significó la diseminación discursiva del nacionalsocialismo por fuera de los territorios conquistados por el Tercer Reich en un intento de «infiltrarse» en los mercados cinematográficos iberoamericanos. Este marco, el Ecuador de 1934-1941 es un sencillo ejemplo de la influencia que alcanzó el nacionalsocialismo en la región, tanto en el aspecto político como en el cinematográfico. 
Cabe recalcar que, durante 1933 y 1945, se produjeron en Alemania 1097 películas, de las cuales solo 229 fueron abiertamente de propaganda — según las valoraciones del régimen nazi- $-\mathrm{y}$, de estas, únicamente 96 películas fueron «películas encomendadas por el estado» (Staatsauftragsfilme) que incluían las más importantes filmaciones desde un punto de vista político, por lo que se les otorgó grandes fondos para producción y publicidad. De esta producción, el 50\% fueron historias de amor o comedias, el $25 \%$ dramas como criminalísticos o musicales ${ }^{78}$.

Comparado con el número de producciones realizadas, al Ecuador llegaron pocos filmes de producción alemana durante la época; cuarenta y un estrenos germánicos se pasaron en salas de cine y, de estas películas, únicamente seis largometrajes corresponden a títulos de «propaganda nazi» según las listas consultadas: i) Juana de Arco, estrenada en 1937 en las salas de cine de Quito y Guayaquil; ii) Rosas Negras, estrenada en 1938 en Ecuador; iii) Los Húsares de la muerte, que llegó a Quito en 1939 y a Guayaquil en 1940; iv) Patriotas, que se estrenó en Guayaquil en 1940; v) Romance Real, que se pasó, también en Guayaquil, en 1940; y vi) ;Volva, Volga!, proyectada en los cines de ambas ciudades.

Además, la mayoría de las películas estrenadas en el país fueron operetas y musicales (18), drama (6), comedia (5), romance (3), aventura (3), bélico (2) y ciencia ficción (1).

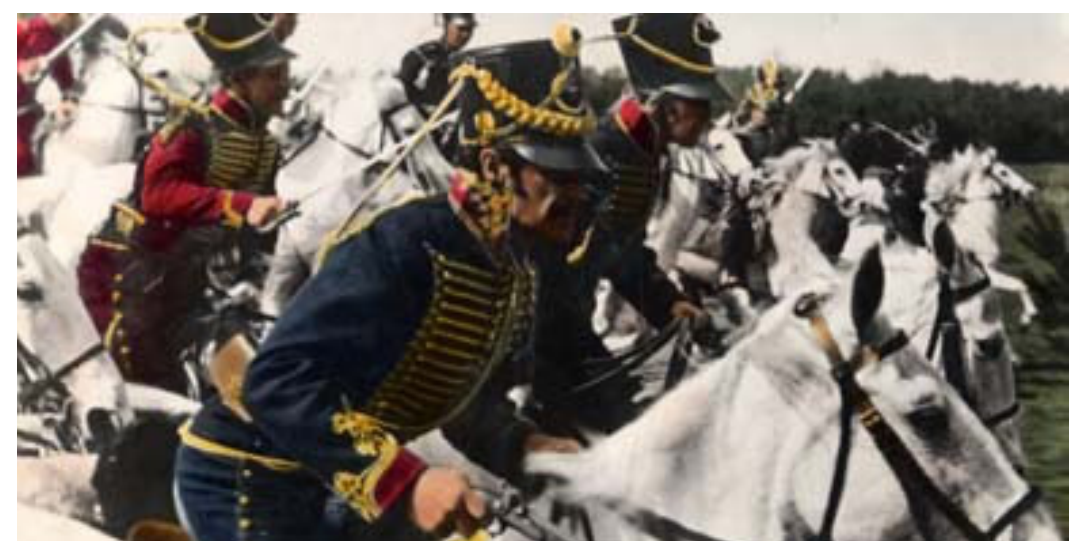

Fotograma de Kolberg (Veit Harlan, 1945).

Por otro lado, las películas de propaganda nazi más reconocidas mundialmente no llegaron a estrenarse en el Ecuador - largometrajes como Kolberg (Veit Harlan, 1945), el Judio Suss, El Judio Eterno, Die Rothschilds (Erich Waschneck, 1940) o El triunfo de la voluntad (Triumph des Willens, Leni Riefenstahl, 1935) - y, si bien hubieron seis largometrajes de propaganda nacionalsocialista, este número tampoco es representativo en comparación con los cuarenta y dos filmes registrados durante la investigación. Además, solo se identificó la proyección de dos noticieros de propaganda: antes de la proyección de la película El Acorazado de Sebastopol en el cine Bolívar de Quito, se pasó el noticiero FOX conjuntamente con el noticiero UFA «con los últimos sucesos mundiales ${ }^{79}$. Este fue el único registro de noticieros transmitidos durante las proyecciones cinematográficas.

Si bien el cine alemán no fue mayoritario en el Ecuador, fue bastante apreciado por la sociedad ecuatoriana por su nivel de tecnicismo y calidad. En general, el cine
[78] David Welch, Propaganda and the German Cinema 19331945 (Londres-Nueva York, I.B. Tauris, 2001), p. 9.

[79] El Comercio, n. ${ }^{\circ} 11.536,8$ de mayo de 1938, p. 3. 
europeo se definía por su profundidad cultural y su fuerte arraigo nacional. El prestigio del cine germánico mostraba a Alemania como un centro cosmopolita, rico, con un fuerte poder tecnológico, una cultura sofisticada y un alto glamour en su industria fílmica. Estos rasgos se evidencian en la apreciación que las propagandas publicadas en los medios de prensa locales. En este aspecto, todos los largometrajes con el sello de la productora UFA fueron patrocinados como sinónimo de calidad y cultura, dignos de la sociedad alemana.

Pese a que el cine alemán durante el Tercer Reich fue una potente herramienta de fascinación, en el Ecuador no pasó a ser más que eso; fascinación. Y vale la pena mencionar que varios estrenos estadounidenses, como argentinos, causaron la misma respuesta en la prensa, y muchos fueron promocionados como «obras maestras»o «imperdibles» películas culturales, por lo que se puede considerar que el cine alemán sirvió, principalmente, para familiarizar la cultura popular germana dentro de los territorios más alejados y «neutrales» del Tercer Reich.

La lucha ideológica entre Ejistas y Aliados por el territorio latinoamericano se concretó con la conformación de la OIAA presente en varios países de la región. En el Ecuador el Comité Coordinador de la OIAA trabajó fuertemente en el ámbito cultural y educativo. En primer lugar, para frenar el avance del nazismo por medio de propaganda antinazi, tanto en los grandes centros urbanos como en las poblaciones más rurales de todo el país y, en segundo lugar, para fortalecer los ideales democráti$\cos$.

La intervención de la OIAA significó la diseminación de la cultura cinematográfica dentro de los poblados más pequeños y alejados de los centros urbanos. De hecho, es muy probable que la primera película que hayan visto en el campo ecuatoriano haya sido, directamente, propaganda antinazi.

El cine en el Ecuador permitió modernizar la vida cotidiana brindando información explícitamente relacionada con salud, higiene y valores progresistas vinculados tanto a lo social como a lo económico y productivo. Si no hubiera sido por la intervención de la OIAA, no se hubiera demostrado en la historia del cine ecuatoriano que el entretenimiento es mucho más que un simple placer.

Lista de películas alemanas estrenadas en Ecuador 1934-1941.

\begin{tabular}{|c|c|c|c|c|c|}
\hline No. & $\begin{array}{c}\text { Año de } \\
\text { estreno } \\
\text { mundial }\end{array}$ & $\begin{array}{c}\text { Año de estreno } \\
\text { en Ecuador }\end{array}$ & Película & Director & Género \\
\hline $\mathbf{1}$ & S/D & 1935 & Internado para señoritas & S/D & S/D \\
\hline $\mathbf{2}$ & 1934 & 1935 & Entre dos corazones & Herbert Selpin & Comedia \\
\hline $\mathbf{3}$ & 1934 & 1936 & Desfile de Primavera & Géza von Bólvary & Comedia \\
\hline $\mathbf{4}$ & 1933 & 1936 & La sinfonía inconclusa & Willi Forst & Opereta \\
\hline $\mathbf{5}$ & 1935 & 1936 & La Carmen Rubia & Viktor Jansen & Musical \\
\hline $\mathbf{6}$ & 1934 & 1936 & Carnaval del amor & Karl Lamac & Opereta \\
\hline $\mathbf{7}$ & 1934 & 1936 & La princesa de las Czardas & Georg Jacoby & Opereta \\
\hline $\mathbf{8}$ & 1934 & 1936 & Oro & Karl Hartl & Ciencia \\
\hline
\end{tabular}




\begin{tabular}{|c|c|c|c|c|c|}
\hline 9 & 1932 & 1937 & Ocho chicas en un bote & Erich Waschneck & Musical \\
\hline 10 & 1934 & 1937 & Vals Real & Herbert Maisch & Romance \\
\hline 11 & 1935 & 1937 & Juana de Arco & Gustav Ucicky & Drama \\
\hline 12 & 1935 & 1937 & Barcarola & Gerhard Lamprecht & Opereta \\
\hline 13 & 1933 & 1937 & Victor y Victoria & Reinhold Schünzel & Musical \\
\hline 14 & 1935 & 1937 & Casta Diva & Carmine Gallone & Musical \\
\hline 15 & 1936 & 1937 & Olimpiadas de Berlín & Leni Riefenstahl & Documental \\
\hline 16 & 1934 & 1937 & El hijo perdido & Luis Trenker & Drama \\
\hline 17 & 1933 & 1937 & Yo y la Emperatriz & Friedrich Hollaender & Musical \\
\hline 18 & $\mathrm{~S} / \mathrm{D}$ & 1937 & $\begin{array}{l}\text { La familia lo desea o } \\
\text { Un Matrimonio inglés }\end{array}$ & $\mathrm{S} / \mathrm{D}$ & $\mathrm{S} / \mathrm{D}$ \\
\hline 19 & 1935 & 1938 & Rosas negras & Paul Martin & Opereta \\
\hline 20 & 1935 & 1938 & Madrecita & Herman Kosterlitz & Comedia \\
\hline 21 & 1935 & 1938 & Noches de San Petersburgo & E.W. Emo & Musical \\
\hline 22 & 1935 & 1938 & Los 100 días de Napoleón & Franz Wentlzler & Drama \\
\hline 23 & 1933 & 1938 & El hijo del Zar & Victor Janson & Opereta \\
\hline 24 & 1936 & 1938 & Acorazado Sebastopol & Karl Anton & Bélico \\
\hline 25 & 1936 & 1938 & $\begin{array}{l}\text { Miguel Strogoff o } \\
\text { El correo del Zar }\end{array}$ & Richard Eichberg & Aventura \\
\hline 26 & $\mathrm{~S} / \mathrm{D}$ & 1938 & Catalina & $\mathrm{S} / \mathrm{D}$ & $\mathrm{S} / \mathrm{D}$ \\
\hline 27 & 1935 & 1939 & $\begin{array}{c}\text { Dos mundos o La tragedia de } \\
\text { una raza }\end{array}$ & Georg Jacoby & Comedia \\
\hline 28 & 1936 & 1939 & La indómita & Johannes Meyer & Romance \\
\hline 29 & 1937 & 1939 & Encantos de Bohemia & Géza von Bólvary & Musical \\
\hline 30 & 1937 & 1939 & Los Húsares de la muerte & Karl Hartl & Bélico \\
\hline 31 & $\mathrm{~S} / \mathrm{D}$ & 1939 & La princesa Turandot & Gerhard Lamprecht & Musical \\
\hline 32 & 1936 & 1939 & Tu eres mi felicidad & Karl Heinz Martin & Opereta \\
\hline 33 & 1934 & 1940 & La patrulla de la muerte & Gustav Fröhlich & Aventura \\
\hline 34 & 1937 & 1940 & Patriotas & Karl Ritter & Drama \\
\hline 35 & 1937 & 1940 & Tragedia en los Alpes & Louis Trenker & Aventura \\
\hline 36 & 1938 & 1940 & Romance Real & Josef von Báky & Romance \\
\hline 37 & 1937 & 1940 & Ensueños & $\begin{array}{c}\text { Douglas Sirk, Serge } \\
\text { de Poligny }\end{array}$ & Comedia \\
\hline 38 & 1937 & 1940 & El murciélago & $\begin{array}{c}\text { Paul Verhoeven, Hans } \\
\text { H. Zerlett }\end{array}$ & Opereta \\
\hline 39 & 1937 & 1940 & $\begin{array}{l}\text { La estrella de Viena o } \\
\text { La golondrina cautiva }\end{array}$ & Detlef Sierck & Musical \\
\hline 40 & 1937 & 1940 & Truxa & Hanns Zerlett & Drama \\
\hline 41 & 1936 & 1940 & ¡Volga, Volga! & Alexandre Volkoff & Drama \\
\hline 42 & 1937 & 1941 & El soberano & Veit Harlan & Drama \\
\hline
\end{tabular}




\section{FUENTES PRIMARIAS}

Hemeroteca de la Biblioteca Ecuatoriana Aurelio Espinosa Pólit (Quito)

Archivo Histórico del Ministerio de Relaciones Exteriores Alfredo Pareja Diazcanseco del Ecuador.

Archivo de la Cinemateca Nacional del Ecuador.

Academia Nacional de Historia del Ecuador.

Aufstellung von Verbotsfilmen laut Übergabelisten der Vorfolgefirmen ${ }^{80}$ (2012).

Liste Vorbehaltsfilme ${ }^{81}$ (1967).

\section{FUENTES HEMEROGRÁFICAS}

Diario El Comercio (1934-1942)

Diario El Telégrafo (1934-1942)

Diario Antinazi (1942)

Diario La Defensa (1940-1942)

Diario El Día (1934-1941)

Diario El Debate (1934-1941)

Diario Vida Obrera (1934-1941)

Diario Regenerador (1934-1941)

\section{BIBLIOGRAFÍA}

Arendt, Hannah, Los orígenes del totalitarismo, Parte III: «Totalitarismo» (Madrid, Alianza Editorial, 1987).

Croci, Paula y KOGAN Mauricio, Lesa humanidad: el nazismo en el cine (Buenos Aires, La Crujía, 2003).

Estrada, Jenny, Segunda Guerra Mundial, lista negra en Ecuador (Quito, Cámara Ecuatoriana del Libro, 2006).

Garden, Ian, The Third Reich's Celluloid War. Propaganda in Nazi Feature Films, Documentaries and Television (Gloucestershire, The History Press, 2012).

[80] Lista de películas prohibidas según las sublistas de empresas productoras.

[81] Lista de películas de reserva.

GiL, Emiliano y CANELA, Antonio, «La migración europea al Ecuador (19351955). La visión diplomática de la llegada de colectivos problemáticos: los judíos» (CHASQUI. Revista Latinoamericana de Comunicación, n. ${ }^{\circ}$ 138, noviembre 2018).

GómEz, Esteban, Análisis de la ruptura de las relaciones bilaterales Ecuador-Ale mania en 1942 (Tesis de Maestría, FLACSO Sede Ecuador, 2017). 
Granda, Wilma, Cronología de la Cultura Cinematográfica en el Ecuador 19011986 (Quito, Casa de la Cultura Ecuatoriana, 1987).

-, Cine Silente en Ecuador (Quito, Casa de la Cultura Ecuatoriana - Cinemateca Nacional, 1995).

HaLl, Melven y PECK, Walter, Wings for the Trojan Horse (Foreign Affairs, Council of Foreign Relations, enero de 1941).

Hobsbawm, Eric, Historia del siglo XX (Buenos Aires, Crítica, 2011).

Jarvinen, Lisa, y Peredo-Castro, Francisco, «Penetrating the Spanish-Speaking Film Markets, 1936-1942», en Roel Vande Winkel y David Welch (eds.), Cinema and the Swastika. The International Expansion of Third Reich Cinema, (Londres, Palgrave Macmillan, 2011).

KeRSFFeld, Daniel, Antinazi: Ecuador y el movimiento de lucha contra el nazismo durante la Segunda Guerra Mundial (Quito, Universidad Andina Simón Bolívar Sede Ecuador, 2015).

—, «Difusión, denuncia y confrontación del nazismo en Ecuador» (Buenos Aires, Publicación del Congreso Judío Latinoamericano, 2016).

-, La migración judía en Ecuador: ciencia, cultura y exilio, 1933-1945 (Quito, Academia Nacional de Historia, 2018).

Kreuter, María Luise, ¿Dónde queda el Ecuador? Exilio en un país desconocido desde 1938 hasta finales de los años cincuenta (Ecuador, Abya-Yala, 1997).

Lauderbaugh, George, «Estados Unidos y Ecuador durante la Segunda Guerra Mundial: conflicto y convergencia», en Beatriz Zepeda (comp.), Ecuador: relaciones internacionales a la luz del bicentenario (Quito, FLACSO Sede Ecuador, 2009).

LunA, Milton, Aula del siglo XXI: Historia y biografias del Ecuador (Quito, Cultural S.A., 2001)

MÉriguet, Pablo, Historia del Movimiento Antifascista del Ecuador (1941-1944) (Quito, Universidad Católica del Ecuador PUCE, 2016).

Mériguet, Raymond, Antinazismo en el Ecuador. Años 1941-1944 (Quito, R. Mériguet Cousségal,1988).

NaZARIo, Luiz, «Nazi Film Politics in Brazil, 1933-42», en Roel Vande Winkel y David Welch (eds.), Cinema and the Swastika. The International Expansion of Third Reich Cinema (Londres, Palgrave Macmillan, 2011) p. 85-98.

Peredo-Castro, Francisco, «Las cinematografías iberoamericanas en la encrucijada 1930-1942» (Archivos de la Filmoteca, n. $^{\circ}$ 40, febrero, 2002), p. 126-147.

PÉREz, Álvaro, «El cine, de la asistencia a "las vistas" a la tecnología 3D» (El Telégrafo, 06 de abril de 2014). Disponible en: https://www.eltelegrafo.com.ec/ noticias/quito/1/el-cine-de-la-asistencia-a-las-vistas-a-la-tecnologia-3d.

Pérez Pimentel, Rodolfo, Ecuador Profundo (Guayaquil, Universidad de Guayaquil, 1988), Tomo IV.

Purcell, Fernando, «Cine, propaganda y el mundo de Disney en Chile durante la Segunda Guerra Mundial» (Historio, n. ${ }^{\circ}$ 43, vol. II, julio-diciembre 2010). Disponible en: https://scielo.conicyt.cl/scielo.php?script=sci_arttext\&pi $\mathrm{d}=\mathrm{S} 0717-71942010000200005$

Rentschler, Eric, The Ministry of Illusion. Nazi Cinema and its Afterlife (Cambridge, Harvard University Press, 1996).

SAdoul, Georges, Historia del Cine Mundial (México, Siglo XXI, 1980).

SCHULTE, Linda, Entertaining the Third Reich: Illusions of Wholeness in Nazi Cinema 
(Durham NC, Duke University Press, 1996).

ToBAR, Julio, Informe a la Nación del ministro de Relaciones Exteriores (Quito, Imprenta del Ministerio de Gobierno, 1941).

Vande Winkel, Roel y WELCH, David (eds.) Cinema and the Swastica. The International Expansion of Third Reich Cinema, (Londres, Palgrave Macmillan, 2011).

WeISER, Benno, «Una historia de la guerra», en Un blog para leer (2014). Disponible en: http://mdarena.blogspot.com/2014/06/una-historia-de-la-guerra.html

Welch, David, Propaganda and the German Cinema 1933- 1945 (Londres-Nueva York, I.B. Tauris, 2001).

Recibido: 15 de junio de 2020 .

Aceptado para revisión por pares: 30 de junio de 2020.

Aceptado para publicación:3 de septiembre de 2020. 
